Project Title: $\quad$ Fast Curing of Composite Wood Products

Recipient: $\quad$ Institute of Paper Science and Technology

Georgia Institute of Technology

$50010^{\text {th }}$ St., NW, Atlanta, GA 30318

Award Number: DE-FC36-01G010625

Subcontractors: T.J. Elder, USDA Laboratory

Southern Research Station, 2500 Shreveport Highway

Pineville, LA 71360

Other Partners: Georgia-Pacific Resins, Inc.

Louisiana-Pacific Corporation

Weyerhaeuser OSB Business

Contact(s): $\quad$ Arthur J. Ragauskas, 404-894-9701, arthur.ragauskas@ipst.edu

Project Team: $\quad$ AF\&PA Agenda 2020 Capital Effectiveness - Task Group, United

States Department of Energy, Elmer H. Fleischman//INEEL/US

\title{
Project Objective:
}

The overall objective of this program is to develop low temperature curing technologies for UF and PF resins. This will be accomplished by:

- Identifying the rate limiting UF and PF curing reactions for current market resins;

- Developing new catalysts to accelerate curing reactions at reduced press temperatures and times.

In summary, these new curing technologies will improve the strength properties of the composite wood products and minimize the detrimental effects of wood extractives on the final product while significantly reducing energy costs for wood composites. 


\section{Background:}

The low cost and proven performance of urea-formaldehyde (UF) and phenolformaldehyde $(\mathrm{PF})$ resins have made them the most important adhesive systems for composite wood products such as, oriented strandboard (OSB), medium-density fiberboard (MDF), and particleboard (PB). Both UF and PF are most commonly applied to wood fibers, particles, and veneer as aqueous solutions. PF resins are manufactured from phenol and formaldehyde and have an affinity for wood surfaces. In the presence of sodium hydroxide and heat $\left(215-235^{\circ} \mathrm{C}\right)$, the PF resin polymerizes into a threedimensionally crosslinked network thereby providing bonding. The curing chemistry can be accelerated using organic esters such as, propylene carbonate, methyl formate or triacetin (i.e., $\alpha$ - and $\beta$-sets acceleration). These catalysts decrease press-time by a factor of $2-7$. The inclusion of the ester accelerator also improves the I.B. strength for dry and boiling tests.

UF resins are prepared from urea and formaldehyde and are applied to wood fibers, particles, and flakes as an aqueous solution. These resins are the dominant adhesives for MDF and PB products. This resin has a natural affinity towards wood surfaces and in the presence of heat (190-225 $\mathrm{C}$ ) and an acidic catalyst (or hardener), UF condenses into a 3dimensionally crosslinked network thereby providing bonding.

The formulation of UF resins was initially accomplished using a two-stage alkaline/acid set of reactions. The use of acid catalysts has significantly improved the curing process providing improved curing rates and products. Neither UF nor PF resins are chemically attached to the wood fibers; instead, the adhesion is attributed to secondary bonding and/or physical bonding. The lack of chemical bonding to wood makes the physical performance of the cured resins susceptible to the presence of extractives in wood. One of the main differences between PF and UF products lies in the water resistance of PF as opposed to UF. 


\section{Profiling Additives for Enhanced Curing of Composite Wood Resins}

\section{Introduction}

This study is related to the accelerated curing of resins for wood composites such as medium density fiberboard (MDF), particle board (PB) and oriented strandboard (OSB). The latter is frequently manufactured with a phenol-formaldehyde resin whereas ureaformaldehyde (UF) resins are usually used in for the former two grades of composite wood products. One of the reasons that hinder wider use of these resins in the manufacturing of wood composites is the slow curing speed as well as inferior bondability of UF resin. The fast curing of UP and PF resins has been identified as an attractive process development that would allow wood to be bonded at higher moisture contents and at lower press temperatures that currently employed.

Several differing additives have been developed to enhance cure rates of PF resins including the use of organic esters, lactones and organic carbonates. A model compound study by Conner, Lorenz and Hirth (2002) employed 2- and 4-hydroxymethylphenol with organic esters to examine the chemical basis for the reported enhanced reactivity. Their studies suggested that the enhance curing in the presence of esters could be due to enhanced quinone methide formation or enhanced intermolecular $\mathrm{S}_{\mathrm{N}} 2$ reactions. In either case the esters do not function as true catalysts as they are consumed in the reaction and were not found to be incorporated in the polymerized resin product. An alternative approach to accelerated PF curing can be accomplished with the addition amines or amides. The later functionality undergoes base catalyzed hydrolysis yielding the corresponding carboxyl ate and free amine which rapidly reacts with the phenolic methylol groups facilitating polymerization and curing of the PF resin (Pizzi, 1997).

The role of the base in alkaline PF resin formulations has also been extensively explored. Daisy and Leeper (1987) have shown that the replacement of sodium hydroxide with up to $50 \%$ by weight potassium hydroxide provides a superior strandboard and plywood. Park et al. (1999) has shown that the addition of carbonates can also accelerate the cure rates of PF resins and reduce press times. A detailed study by Pizzi et al. (1997) suggests 
the catalytic hardening effect of carbonate is purely due to an acceleration of the polycondensation reactions involved in cured resin formation.

To-date, the curing of UF resins for wood products has been explored using the addition of inorganic and/or organic Bronsted acids such as maleic, formic or phosphoric acid. Alternatively, the use of latent hardeners such as ammonium sulfate and chloride which dissociate in water have been employed (Dunky, 1998, Tomita and Hse, 1992). Clearly the need for new UP and PF curing agents to lower the cost and energy of preparing wood composites and to enhance the overall performance and properties of wood composites are needed.

Cationic starch, which has been not reported as a curing agent for PF and UF resins, is important in papermaking technologies. Although there are a number of cationic starch derivatives available only two tertiary and quaternary amino compounds are industrially used. The degree of substitution for a cationic starch is typically 0.02-0.05. Cationic starch is used to help form stable emulsions from AKD and ASA sizing agents in papermaking. Also, starch is available for improving dry strength and drainage of paper (Bobu et al., 1997). On the other hand, it has been well known that starch can be used as a resin extender (Bagley et al., 1977). The extender, which has some adhesive action, is common in plywood adhesive mixtures. The purpose of an extender such as wheat flour is to improve panel properties and reduce production costs. It is well known that partial replacement of a commercial liquid PF resin with wheat flour has an effect on physical properties. Physical and mechanical properties in some instance were observed to improve with the addition of extender and filler agents (Baldwin, 1995). Recently Sanjuan et al.(1999) reported that a mixture of PF resins with organosolv lignin results in an increase in tension strength. Robertson and Robertson (1977) reported on the effect of various additives such as clay, nutshell flour, and corn starch in PF and UF resins. Also, the use of non-reducing sugar has been reported for the replacement of particleboard adhesive (Corner et al., 1986). The additives did not significantly affect thermal cure characteristics, even though adhesives with additives had considerably higher viscosity than without additives (Johnson and Kamke, 1994). However, Janowiqk and Carlson 
(1998) indicated that the replacement of UF resins with carbohydrate based methyl glucosides and sodium lignosulphonate compounds causes the gel time to increase except when ammonium lignosulfate acts as the extender. A treatment of $25 \%$ ammonium lignosulfonate lead to a slightly decreased gel time.

This study is focused on examining a series alternative curing agents for UP and PF resins that accelerate cure reactions at reduced press temperature and time. First, new fast curing chemicals are to be selected by a gel-test, which is a common procedure used to determine the cure rate. Second, the resins cured by an effective cure agent were subjected to further investigation for the synthesis of composite wood products.

\section{EXPERIMENTAL}

\section{Materials and Chemicals.}

Pine, aspen and mixed hardwood strands were acquired from our industry partners these were screened to remove fines and the accepts had dimensions of $(0.5-0.7 \mathrm{~mm}) \times(20-$ $30 \mathrm{~mm}) \times(20-40 \mathrm{~mm})$. The extractives moisture content of the pine, aspen and mixed hardwood strands was determined by Soxhlet extraction for 24 hours with 1.00:0.42 ratio of ethanol to toluene. The moisture content was determined by drying wood samples to constant weight at $105{ }^{\circ} \mathrm{C}$. The results of these studies are summarized in Table I.1.

Table I.1: Characterization of Commercial Wood Strands

$$
\% \text { Extractives \% Water Content }
$$

Pine

Aspen

4.4

3.7

Mixed Hardwood

4.4

7.1

The screened wood strands were stored near $0{ }^{\circ} \mathrm{C}$ prior to use.

Commercial wood resins and indrawax 033 were provided by a vendor. The UF resin had a pH of 7.5 and was $64.4 \%$ solids. Two PF resins referred to in this report as PFa and PFb 
had $\mathrm{pH}$ values of 11.2 , and $9.7 \%$ solids of 46.2 and $58.8 \%$, respectfully. The cationic starch (2-hydroxy-3-trimethylamino-chloride propyl ether derivative: $0.33 \%$ nitrogen) and corn starch were obtained from Hercules Inc. All other chemicals including propylene carbonate, methyl formate, triacetin, tetraethylenepentamine and powered ammonium Y zeolite were commercially purchased from Aldrich Chemical Company and used as received.

\section{Screening Cure Additives for UF and PF Resins}

The ability of select additives to enhance the cure rate of UF and PF resins was assessed by adding a fixed mass of the additive to a solution of commercial resin. Following the standard ASTM D 3056-00 method, a sample of the resin $(10.00 \mathrm{ml})$ was immersed in an oil-bath heated to $100.0^{\circ} \mathrm{C}$, the additive was immediately added to the resin solution and stirring was initiated. Gel time was established employing a Sunshine Gel timer which was halted upon formation of a cured resin. Control experiments were accomplished in the exact same manner except that no curing agent was added. The results of these studies are summarized in Table I.2 - .11.

\section{RESULTS AND DISCUSSION}

Additive Screening Studies: Our initial additive curing studies were directed at assessing the effects of known curing agents including methyl formate, propylene carbonate and tricetin and tetraethylene amine on the commercial resins employed in this study. As shown in Table I.2, the well-known esters used as the catalyst for resin curing have a prominent effect on gelation time of resins, especially in PFa. The addition of propylene carbonate reduces gel time in the PF resin, while it has only a small effect on gelation time on UF resins. It is known that the decomposition products of the ester under high $\mathrm{pH}$ can react with phenolic carbanions, resulting in higher functionality. This increased functionality may enhance the formation of a methyol group between the 
phenol and formaldehyde (Park and Riedl, 2000; Pizzi and Stephanous, 1993). It has been reported that the addition of considerable amounts of esters was found to accelerate the curing of the resins to extremely short curing times. These studies announced that the strength and dissociation of acid involved in the esters could be related to the rate of accelerated curing of the resins.

Table I.2: Effect of known Cure Additives on Resin Gel Time/minutes

\begin{tabular}{cccccc}
\hline Control & $\begin{array}{c}10 \% \text { methyl } \\
\text { Formate }\end{array}$ & $\begin{array}{c}10 \% \text { propylene } \\
\text { carbonate }\end{array}$ & $10 \%$ triacetin & $10 \%$ para- & $\begin{array}{c}10 \% \\
\text { tetraethylene- } \\
\text { pentamine }\end{array}$ \\
\hline 35.9 & 9.6 & 34.8 & 28.0 & 25.9 & no effect \\
30.5 & 15.4 & 7.0 & 18.1 & 19.2 & 20.0 \\
23.6 & $<0.08$ & 0.4 & 1.3 & 9.4 & 9.9 \\
\hline
\end{tabular}

The impact of employing a cationic starch on gel times was evaluated for the PF and UF resins as summarized in Table I.3. In addition to the cationic starch, a corn starch was used to evaluate the effects of the cationic group on the starch.

Table I.3: Effect of Cationic Starch and Corn Starch on Resin Gel Time/minutes

\begin{tabular}{lccc}
\hline Kinds of resin & Control & $10 \%$ starch & $10 \%$ Cationic Starch \\
\hline UF resin & 35.9 & 20.3 & 17.4 \\
$\mathrm{PF}_{\mathrm{b}}$ & 30.5 & 25.1 & 15.2 \\
$\mathrm{PF}_{\mathrm{a}}$ & 23.6 & 19.1 & 6.2 \\
\hline
\end{tabular}

As shown in Table I.3, the cationic starch was found to have a beneficial effect at accelerating the cure time of both UF and PF resins. Clearly, the quaternary amino group grafted to the starch appears to have a beneficial effect for the cationic starch enhancing UF and PF gel times. The addition of cationic starch into PFa appeared to be more effective than the other resins. 


\section{VARIATION OF GEL TIME ACCORDING TO THE AMOUNTS OF CATIONIC STARCH}

Given the promising results observed in Table I.3 a second series of gel studies were undertaken to evaluate the dose response of the cationic starch.

Table I.4: Dosage Effect of Cationic and Corn Starch on Resin Gel Time/minutes.

\begin{tabular}{|c|c|c|c|c|c|c|}
\hline Resin & $5 \%$ Starch & $\begin{array}{c}5 \% \\
\text { Cationic } \\
\text { Starch }\end{array}$ & $\begin{array}{c}10 \% \\
\text { Starch }\end{array}$ & $\begin{array}{c}10 \% \\
\text { Cationic } \\
\text { Starch }\end{array}$ & $\begin{array}{c}15 \% \\
\text { Starch }\end{array}$ & $\begin{array}{c}15 \% \\
\text { Cationic } \\
\text { Starch }\end{array}$ \\
\hline UF & 32.1 & 29.5 & 20.3 & 17.4 & 14.1 & 12.0 \\
\hline $\mathrm{PFb}$ & 25.5 & 22.9 & 25.1 & 15.2 & 23.3 & 8.0 \\
\hline $\mathrm{PFa}$ & 19.2 & 18.8 & 19.1 & 6.2 & 17.8 & 2.9 \\
\hline
\end{tabular}

As summarized in Table I.4 the gel time of the resins appeared to decrease with an increased addition of starch. Cationic starch has a greater effect on curing of PF resin than on UF resin. In UF resins, cationic starch has no significantly different curing effect in comparison with a general starch even though it is at $15 \%$ addition of cationic starch. The addition of $15 \%$ cationic starch leads to rapidly shortened gel-times for all types of resins. However, it is not likely that the gel is harder than in the case with a smaller charge of cationic starch. Therefore, it would appear that the optimum dosage is around $10 \%$ of cationic starch based on the solid content in the resins.

\section{EFFECT OF CATIONIC STARCH AND ESTER CHEMICAL MIXTURE ON GEL TIME}

Based on comments from our industrial partners reviewing this program, an additional series of additive experiments were undertaken to evaluate the potential synergistic interactions between established cure additives and the observed cationic starch to the resin mixture. On the basis of the previous additive gel test results (Table I.2), methyl formate was used for UF resin, propylene carbonate for PF resins. 
Table I.5: Effect of Cationic Starch and Ester Additives on Resin Gel Times/minutes

\begin{tabular}{l|c|c|c|c}
\hline \multirow{2}{*}{ Kinds of resin } & \multicolumn{2}{|c|}{$10 \%$ Cationic Starch } & \multicolumn{2}{c}{ No Cationic Starch } \\
\cline { 2 - 5 } & $\begin{array}{c}1 \% \text { methyl } \\
\text { formate }\end{array}$ & $\begin{array}{c}1 \% \text { propylene } \\
\text { carbonate }\end{array}$ & $\begin{array}{c}1 \% \text { methyl } \\
\text { formate }\end{array}$ & $\begin{array}{c}1 \% \text { propylene } \\
\text { carbonate }\end{array}$ \\
\hline UF resin & 11.7 & -- & 18.8 & -- \\
$\mathrm{PFb}$ & -- & 11.7 & -- & 16.7 \\
$\mathrm{PFa}$ & -- & 5.1 & -- & 12.2 \\
\hline
\end{tabular}

As summarized in Table I.5, the addition of cationic starch appears to create an effective enhanced gelation time. In particular, the addition of $10 \%$ cationic starch and $1 \%$ methyl formate on UF resin was found to accelerate gelation time similar to that for a $10 \%$ addition of methyl formate. It has been shown that the esters such as methyl formate and propylene carbonate are very effective at decreasing of press time due to accelerate the curing time of the resin. However, the only problem in such a system is the use of the relatively high proportion of the ester agent, which is typically between $10 \%$ and $15 \%$ based on solid content of the resin (Batubenga et al., 1995). The addition of cationic starch together with the esters is helpful for decreasing the use of the esters. Furthermore, the decreased amount of esters is capable of improving the distribution of the resins in a spray since it partially prevents hardening of the resins.

\section{EFFECT OF AMIDES ON GEL TIME OF RESINS}

The impact of amides on the gelation time with and without cationic starch was also explored as shown in Table I.6. The amides selected included formamide and N,Ndimethylformamide. It has been shown that formamide can be dissociated to formic acid and an ammonia. As previously described, $\mathrm{NH}_{3}$ can react with the hydroxylphenyl alcohol of PF resins to lead to a new linkage. 
Table I.6: Effect of Amides on Resin Gel Times/min

\begin{tabular}{|c|c|c|c|c|c|c|}
\hline Resin & $1 \%$ & $\begin{array}{c}1 \% \text { plus } \\
10 \% \text { Cationic } \\
\text { Starch }\end{array}$ & $5 \%$ & $\begin{array}{c}5 \% \text { plus } \\
10 \% \text { Cationic Starch }\end{array}$ & $10 \%$ & $\begin{array}{c}10 \% \text { N,N- } \\
\text { Dimethylformamide }\end{array}$ \\
\hline UF & -- & -- & -- & -- & 23.6 & +39 \\
\hline $\mathrm{PFb}$ & -- & -- & -- & -- & 20.4 & 23.5 \\
\hline $\mathrm{PFa}$ & 11.8 & 4.5 & 5.7 & 3.9 & 4.3 & 18.7 \\
\hline
\end{tabular}

Formamide has a positive effect on curing of PF3a resin which could be attributed, in part, to the higher starting $\mathrm{pH}$. The gel time of the resin decreased as the formamide addition increased. Dimethylformamide was found to have a beneficial effect on the curing of the PF resins while the amide has no effect on UF resins which is consistent with literature reports. Interestingly, the addition of cationic starch to the amide gel tests was shown to be beneficially accelerate the gel time of PFa resin. The gel time levels obtained by the addition of cationic starch with $1 \%$ formamide are similar to that obtained with $10 \%$ formamide.

\section{EFFECT OF ALDEHYDES ON GEL TIME}

The results of investigating several types of aldehydes to enhance gel time for UF and PF resins were investigated as presented in Table I.7. Formaldehyde is the main component in the preparation for resins. In addition, other aldehydes such as paraformaldehyde can be used for preparing resins. This is most likely to cause the coplymerization with resins. It is expected that phenols remaining without methyolation in PF resins that could form other intermediates for condensation with aldehydes. As summarized in Table 6, the aldehydes used in this test have limited effects on the gelation of resin. The gel time of PF resins is reduced only by 2-8 minutes. Thus, it is not likely that the aldehydes reacted with phenol as much as formaldehyde. 
Table I.7: Effect of Aldehydes on Resin Gel Time/min.

\begin{tabular}{c|c|c|c}
\hline Resin & $\begin{array}{c}10 \% \text { Benzaldehyde- } \\
\text { Dimethyl acetal }\end{array}$ & $\begin{array}{c}10 \% 1,3-\text { Dioxolane } \\
\text { formal }\end{array}$ \\
\hline UF resin & 35.3 & 35.3 & +38 \\
$\mathrm{PFb}$ & 22.8 & 26.3 & 26.8 \\
$\mathrm{PFa}$ & 19.0 & 23.0 & 21.6 \\
\hline
\end{tabular}

\section{ASSESSMENT OF ALTERNATIVE INORGANIC ADDITIVES ON RESIN GEL TIME}

\section{Effect of ammonium formate and calcium carbonate on gel time of resins}

Ammonium formate and calcium carbonate were examined to evaluate their efficiency at accelerating the curing of properties of the resin under study (see Table I.8). Ammonium formate was selected since it was expected to have a similar effect to methyl formate, which had a good effect on resin curing. In addition, ammonium ions of ammonium formate are likely to dissociate to ammonia, which may enhance the linkages in resins.

Table I.8: Effect of Ammonium Formate and Calcium Carbonate on Resin Gel Times/min.

\begin{tabular}{l|c|c|c}
\hline \multirow{2}{*}{ Kinds of resin } & \multicolumn{2}{|c|}{ Ammonium Formate } & Calcium carbonate \\
\cline { 2 - 4 } & $5 \%$ & $10 \%$ & $10 \%$ \\
\hline UF resin & 2.9 & 3.7 & +42 \\
$\mathrm{PFb}$ & 24.5 & 28.6 & 23.7 \\
$\mathrm{PFa}$ & 15.0 & 15.1 & 18.0 \\
\hline
\end{tabular}


Ammonium formate prepared as a 50\% solution was added to the resins. The gelation times for UF resins appear to be rapidly accelerated by ammonium formate, while PF resins appear to have a less significant effect. Ammonium formate has the greatest effect on curing of UF resins among the all chemicals tested so far. As for the other esters, ammonium formate has a greater effect on $\mathrm{PFa}$ with high $\mathrm{pH}$ than $\mathrm{PFb}$. $\mathrm{A} 10 \%$ addition of ammonium formate does not improve the gel time compared to a 5\% addition. Indeed, it may actually introduce more water to the resin-ammonium formate mixture. On the other hand, calcium carbonate has only a small effect on curing of the resins.

Following some, preliminary experiments one last type of inorganic additive was examined as a potential catalyst which was a powered $\mathrm{Y}$ zeolite. The results of resin gel time testing with this additive are summarized in Table I.9.

Table I.9: Effect of Y Zeolite on Resin Gel Time/minutes.

\begin{tabular}{|c|c|c|c|c|c|}
\hline Resin & Control & $5 \%$ Zeolite & $1 \%$ Zeolite & $0.5 \%$ Zeolite & $0.1 \%$ Zeolite \\
\hline UF & 33.8 & 1.4 & 2.0 & 3.4 & 24.1 \\
\hline $\mathrm{PFb}$ & 25.5 & 24.6 & -- & -- & -- \\
\hline $\mathrm{PFa}$ & 17.2 & 16.2 & -- & -- & -- \\
\hline
\end{tabular}

These results are extremely notable for enhancing the gel performance of UF resins and is certainly one of the most effective additive cure effect we have observed for UF resins and out performs the know inorganic additives reported in Table I.8.

Clay and other mineral fillers have been intensively investigated as a filler component for wood adhesives board products to improve their working properties, performance, and strength. (Orth, 1972, Kozlowski, et al., 1999; Kronotec A.G., 2005) Recently, research studies have developed a new series of clays that are generated by treating clays with a alkyl substituted quaternary ammonium species. This treatment defoliates the clay, yielding structured materials with varying hydrophobic surfaces. The clays used in this report consist of organically modified nanometer scale thick layered magnesium aluminum silicate platelets (Maniar, 2004; Suzuki, 2001; Zeng et al., 2005). The platelets are a few nanometers thick by $70-150$ nanometers in diameter and the surfaces are modified with an organic additive to allow for complete dispersion with hydrophobic 
polymers. These modified clays have been proven to reinforce thermoplastics by enhancing flexural and tensile modulus. Furthermore, these nano-additives have been proven to be effective at improving gas barrier and flame retardant of thermoplastic systems. Their application in composite board products has not been previously examined. We had anticipated clear benefits for improved strength and moisture stability properties for the UF and PF board systems. To evaluate the application of nano-clay materials for board production, we initially evaluated the effects of several common nano-clays on the gelling time of several common UF and PF resins. The effects of nano-clays on gel time for UF and PF resins are summarized in Table I.10.

Table I.10: Effect of Zeolite on Resin Gel Time/minutes.

\begin{tabular}{|c|c|c|}
\hline Resin & UF & PFc \\
\hline No Filler & 27.1 & 9.9 \\
\hline $10 \%$ Natural Montrmorillonite & $>30$ & 8.7 \\
\hline 10\% Nanoclay Modified With & \multicolumn{2}{|c|}{} \\
\hline Dimethyl, benzyl, hydrogenated tallow & $>30$ & 9.7 \\
\hline Dimethyl, dehydrogenated tallow & $>30$ & 9.8 \\
\hline Dimethyl, hydrogenated tallow, 2-ethylhexyl & $>30$ & 9.8 \\
\hline Methyl, tallow, bis-2-hydroxylethyl & $>30$ & 9.9 \\
\hline Methyl dihydrogenated tallow & 2.3 & 9.5 \\
\hline
\end{tabular}

The selective gel benefits for the nanoclay modified methyl dihydrogenated tallow were to some degree, unexpected and as a result we further examined the gel dose response of this additive with UF resin. The dose-gel response studies are summarized in Table I.11.

Table I.11: Effect of Methyl Dihydrogenated Tallow Nano Clay on UF Gel Time/min.

\begin{tabular}{|c|c|c|c|c|c|}
\hline & \multicolumn{5}{|c|}{$\%$ Methyl Dihydrogenated Tallow Nano Clay Added to UF Resin } \\
\hline & $0 \%$ & $2 \%$ & $5 \%$ & $10 \%$ & $20 \%$ \\
\hline UF gel time & 27.1 & 4.8 & 3.1 & 2.3 & 1.6 \\
\hline
\end{tabular}

The results in Table I.9 and .10 suggest that the nanoclay modified with methyl dihydrogenated tallow significantly enhance UF gel times.

In summary, at the completion of these studies we had identified three very promising new class of resin curing agents for both UF and PF resins based on gel time analysis. The next phase of these studies was directed at establishing the applicability of these new 
additives to enhance composite board formation which is reported in the next section of this final report. 


\section{Initial Composite Board Studies With and Without Cure Additives}

Following the successful resin gel studies, the next research objective in this collaborative DOE - industry co-funded program was to prepare a series of composite UF and PF wood composites with and without additives. The objective of these studies was to determine if the observed additive enhanced gel times would yield test composite wood products with improved physical properties.

\section{Experimental}

\section{Lab-Press Studies}

Laboratory composite board formation was accomplished using a Craver Press. 1\% Fluka paraffin wax, $5 \%$ UF or PF (mass with respect to pine strands) resin with or without additives were applied onto the pine strands employing an air sprayer. The blended furnish was then hand felted into a form box with aluminum cauls with a random orientation. Mat consolidation and curing were accomplished using a laboratory hydraulic press $(15.24 \times 15.24 \mathrm{~cm})$. The PF resins treated strands were cured at a press temperature of $176.7^{\circ} \mathrm{F}$ with $2.8 \mathrm{Mpa}$ pressure for 3 minutes and the UF treated strands were treated in a comparable method except the press temperature was $148.9^{\circ} \mathrm{C}$. All boards were conditioned at $20{ }^{\circ} \mathrm{C}$ and $50 \%$ humidity for 72 hrs prior to cutting into $2.54 \mathrm{x}$ $2.54 \mathrm{~cm}$ test specimens for physical testing. Final board densities were $0.62 \mathrm{gr} / \mathrm{cm}^{3}$ $\pm 2.3 \%$

\section{Pilot Plant Studies:}

Pine strands $(11 \mathrm{~kg})$ were placed into a larger mixing drum revolving at $17 \mathrm{rpm}$. The wood chips were mixed for 5 minutes prior to adding Indrawax 033 (1.00\%), PF resin and the cure accelerator. The wood additives were applied to the tumbling wood strands with an atomized sprayer over a period of 10 minutes. After mixing for an additional 10 minutes, the treated wood strands were removed from the mixing drum and utilized for OSB testboards. The resinated furnish was hand felted into a form box with aluminum cauls and then was placed into hot press at $204.4{ }^{\circ} \mathrm{C}$ for $3.25-5.25$ minutes with press pressures of 95 and 120 tons. All boards were post-conditioned at $25{ }^{\circ} \mathrm{C}$ and $70 \%$ 
humidity for four weeks prior to physical testing. Board densities were determined to be $43 \mathrm{lbs} / \mathrm{ft}^{3}( \pm 3.1 \%)$.

\section{Physical Testing of Composite Boards:}

Thickness swelling and water adsorption were measured according to standardized ASTM D1037-99 and DIN52364 protocols (ASTM, 1999). In brief, the test boards were soaked in deionized water at $20.0{ }^{\circ} \mathrm{C}$. After $2.00 \mathrm{hrs}$, the specimens were withdrawn from the water and wiped dry with a paper towel to remove excess water. Increases in weight and thickness during the immersion were calculated on a mass basis and expressed as percentage.

Internal bond strength tests (IB) were performed on board specimens according to specification of ASTM protocol D1037-99 using an INSTRON tester. In brief, a test board specimen of $51 \mathrm{~mm}$ x $51 \mathrm{~mm}$ was attached to a aluminum test blocks on the top and bottom of the board specimen using epoxy adhesives. The test machine secured the aluminum blocks and applied a tension force perpendicular to the specimen surface until the specimen failed. The internal bond was then recorded as the maximum load applied prior to failure.

\section{Results and Discussion}

Our initial board studies were directed at using a laboratory Carver press to make small test samples of composite pine boards using UF, PFa and $\mathrm{PFb}$ resins with and without the zeolite and cationic starch additives. The board were prepared following well established literature procedures and then tested for their water absorption and thickness swelling properties. These two properties were recommended to the researchers from our industrial review panel and they represent two key physical parameters in the performance parameters used to assess the quality of composite board products. 
Table II.1: Physical Testing Results of Composite Pine Strand Board Produced With and Without Cure Accelerators Prepared Employing Carver Press.

\begin{tabular}{|c|c|c|c|}
\hline Composite Board $^{1}$ & $\begin{array}{l}\text { Board Density } \\
\left(\mathrm{g} / \mathrm{cm}^{3}\right)\end{array}$ & $\begin{array}{c}\% \text { Thickness } \\
\text { Swelling }\end{array}$ & $\begin{array}{c}\% \text { Water } \\
\text { Adsorption }\end{array}$ \\
\hline $\operatorname{PFa}(5 \%)$ & 0.656 & 98.4 & 107.8 \\
\hline $\mathrm{PFa}(5 \%)+$ Zeolite $(5 \%)$ & 0.650 & 89.4 & 101.4 \\
\hline $\mathrm{PFa}(5 \%)+$ Cationic Starch (5\%) & 0.664 & 84.8 & 100.1 \\
\hline $\mathrm{PFb}(5 \%)$ & 0.650 & 96.9 & 103.2 \\
\hline $\mathrm{PFb}(5 \%)+$ Zeolite $(5 \%)$ & 0.657 & 88.7 & 98.0 \\
\hline $\mathrm{PFb}(5 \%)+\operatorname{Starch}(5 \%)$ & 0.682 & 81.7 & 95.7 \\
\hline UF $(5 \%)$ & 0.661 & 159.3 & 124.0 \\
\hline UF (5\%) + Zeolite (5\%) & 0.659 & 140.2 & 122.7 \\
\hline UF $(5 \%)+$ Cationic Starch (5\%) & 0.659 & 130.1 & 122.4 \\
\hline
\end{tabular}

${ }^{1} \%$ resin added was based on $\%$ strand weight; $\%$ additive added was based on $\%$ resin weight

The results of the studies presented in Table II.1 demonstrate that the incorporation of the cationic starch and zeolite into composite board was beneficial for both PF and UF resins. In both cases, the addition of these additives to the starting materials prior to board production reduced the thickness swelling and water adsorption properties of the composite board products. Based strictly on a \% mass basis, the cationic starch was more effective at improving board properties over the use of the zeolite.

Based on the success of these studies, additional additive studies were pursued employing the pilot plant composite board press facilities available at Georgia-Pacific Resins, Inc. Decatur, GA. The experimental board synthesis parameters are summarized in Table II.2 
Table II.2: Pilot Plant Production of Composite Wood Boards

Wood Strands:

Mat Dimensions:

Mat Formation:

Target Density:

PFa Resin Content:

Blend Moisture Content:

Max. Press Temperature:

Max. Press Pressure:

Press Time:
$2.10 \mathrm{~kg} / \mathrm{board}$

$40.6 \times 40.6 \times 29 \mathrm{~cm}$

One layer with random orientation

$0.688 \mathrm{gr} / \mathrm{cm} 3$

$3.5 \%$ based on oven dried weight of wood strands

$7.0-7.5 \%$

$204{ }^{\circ} \mathrm{C}$

$95 \& 120$ tons

$3.25-5.25$

Note: Additive charges are base on resin mass

The water absorption and thickness swelling properties of the composite wood boards prepared on the pilot plant press facilities are summarized in Figures II.1 and .2.

Figure II.1: \% Changes in Two Hour Thickness Swelling and Water Absorption Properties for Control and Additive Treated Boards Prepared with PFa Resin on a Pilot Plant Press with 95 and 120 ton Press Pressure.

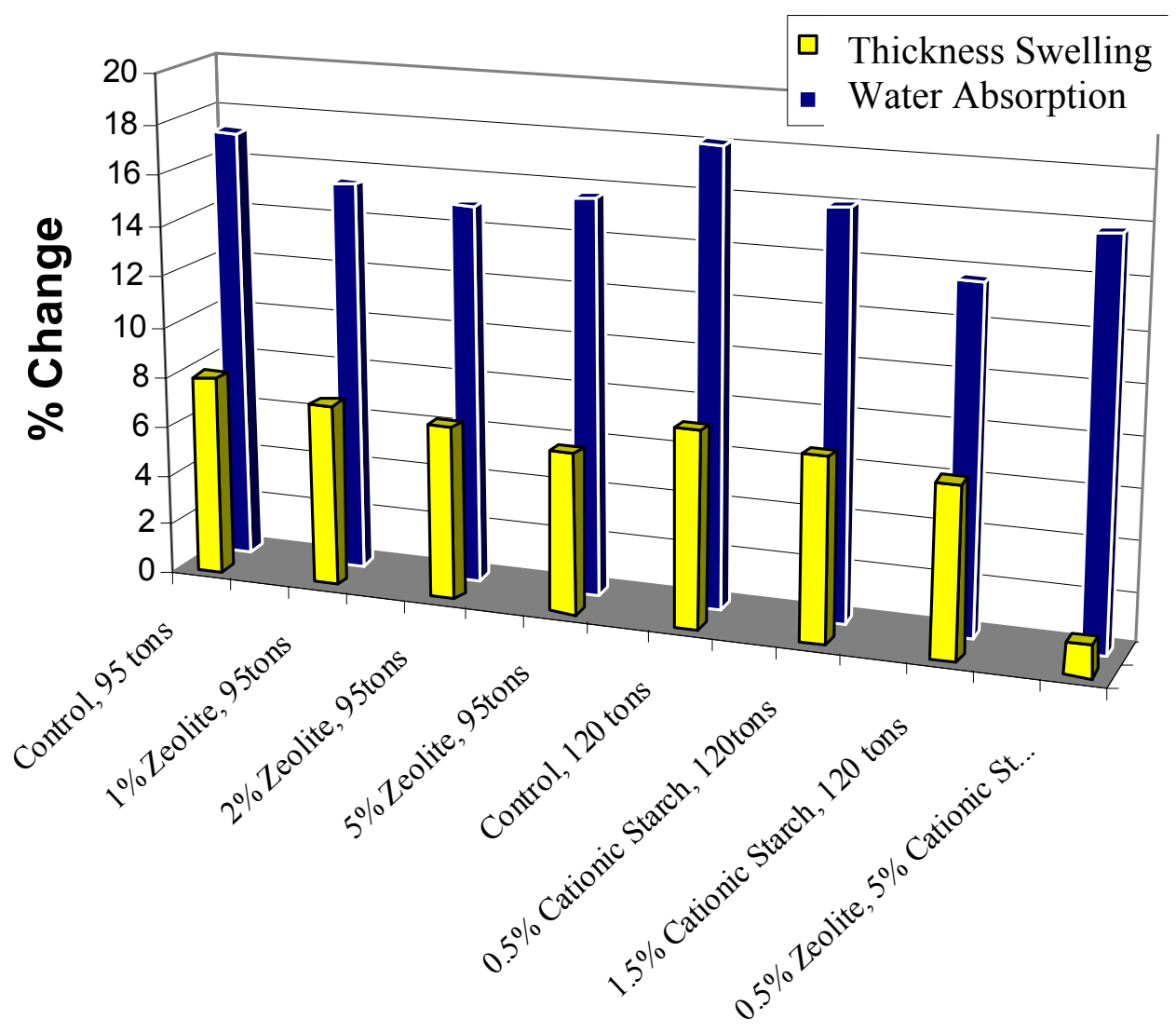


Figure II.2: \% Changes in Twenty-Four Hour Thickness Swelling and Water Absorption Properties for Control and Additive Treated Boards Prepared with PFa Resin on a Pilot Plant Press with 95 and 120 ton Press Pressure.

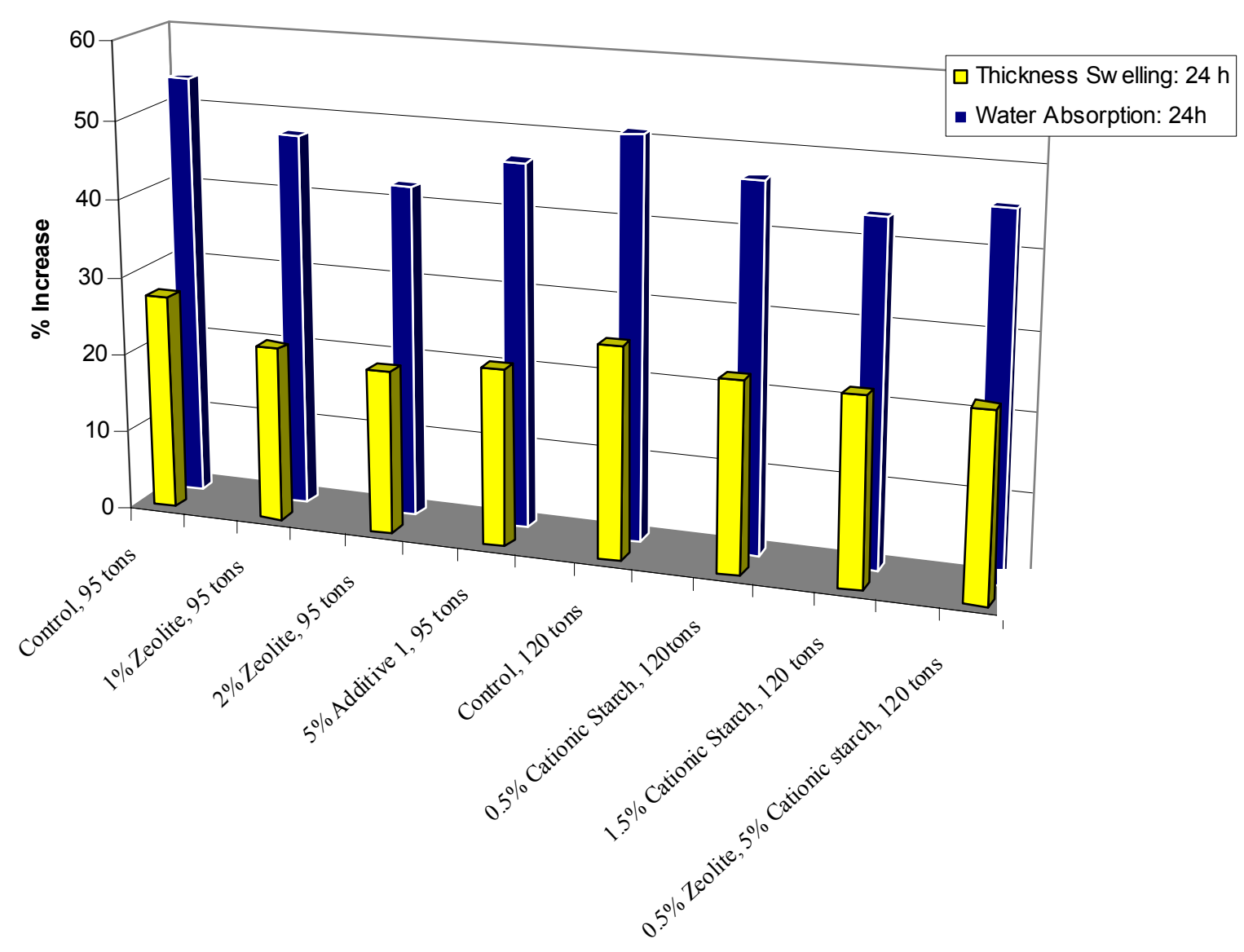

The results summarized in Figures II.1 and II.2 provided several promising trends including the observation that addition of the zeolite or cationic starch additive enhances water stability for short term and long term immersion in water. In addition, the results with the pilot press studies were in agreement with the overall trends that were observed with the laboratory Carver press studies. The addition of the curing additive to the wood strands appears to have greater impact on reducing thickness swelling over water adsorption. Overall, the impact of the additives was more effective at the lower press 
pressures. Furthermore for both the zeolite and cationic starch additives, it was clear that an optimal charge of additive provided the best moisture repellence properties. To further assess the benefits of these two additives, a second set of composite boards were prepared employing the pilot press as described in Table 11.2 and these were evaluated for their internal bond (IB) values following standard ASTM testing methods (see Fig. II.3 for test sample).

Figure II.3 IB-Test Sample.

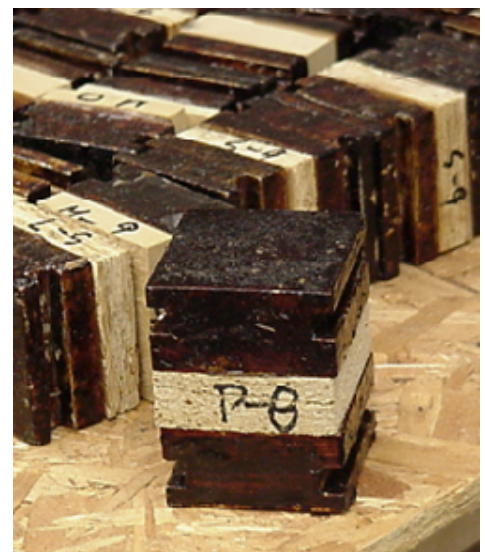

The results of IB-testing the composite boards are summarized in Table II.3. 
Table II.3: IB Testing of Pine Strand - PFa Resin Boards Prepared on Pilot Plant Press Facilities.

\begin{tabular}{|c|c|c|}
\hline PFa Board Production & IB Density $\left(\mathrm{kg} / \mathrm{m}^{3}\right)$ & IB/psi \\
\hline Control 95 ton/4.50 min & 705 & 36.9 \\
\hline Control 95 ton/4.75 min & 692 & 37.8 \\
\hline $1 \%$ Zeolite, 95 ton/4.50 min & 712 & 54.1 \\
\hline $2 \%$ Zeolite, 95 ton/4.50 min & 700 & 45.3 \\
\hline $2 \%$ Zeolite, 95 ton/4.75 min & 722 & 42.5 \\
\hline $5 \%$ Zeolite, 95 ton/4.50 min & 707 & 49.2 \\
\hline \multicolumn{2}{|c|}{734} & 40.0 \\
\hline Control 120 ton/4.75 min & 705 & 42.9 \\
\hline Control 120 ton/5.00 min & 689 & 43.1 \\
\hline $1 \%$ Cationic Starch, 120 ton/4.50 min & 709 & 45.3 \\
\hline $2 \%$ Cationic Starch, 120 ton/4.50 min & & \\
\hline
\end{tabular}

Note: \% additive is a mass reference to resin added.

These results were extremely relevant and promising to the technology developed in this program as it demonstrates that the additives enhance physical strength properties of the composite boards by $10-45 \%$. It furthermore, validates our experimental design and the use of a Carver press for laboratory studies.

The UF-nanoclay gelling results in chapter I suggest that the nanoclay modified with methyl dihydrogenated tallow significantly enhances UF gel times. To examine the application of this nanoclay for composite board production, we prepared a series UF boards with a pine wood particles. The wood furnish was blended with $1 \%$ of paraffin wax (based on particle weight) and hand felted into a form box with aluminum cauls. Mat consolidation and curing were accomplished using a laboratory hydraulic press. The same hot-pressing schedules were used for all the boards employing a maximum temperature of $121{ }^{\circ} \mathrm{C}$. After hot-pressing, the boards were allowed to cool at room 
temperature and then conditioned at $20^{\circ} \mathrm{C}$ and $50 \%$ humidity for 1 week. Six 1 ” x 1 " x 1 " specimens were cut from each board. Thickness swelling and water adsorption were measured according to ASTM D1037. The specimens were soaked in water at $20{ }^{\circ} \mathrm{C}$.

Figure II.3: Impact of Nanoclay Modified with Methyl Dihydrogenated Tallow on Thickness Swelling and Water Absorption of Pine UF Boards.

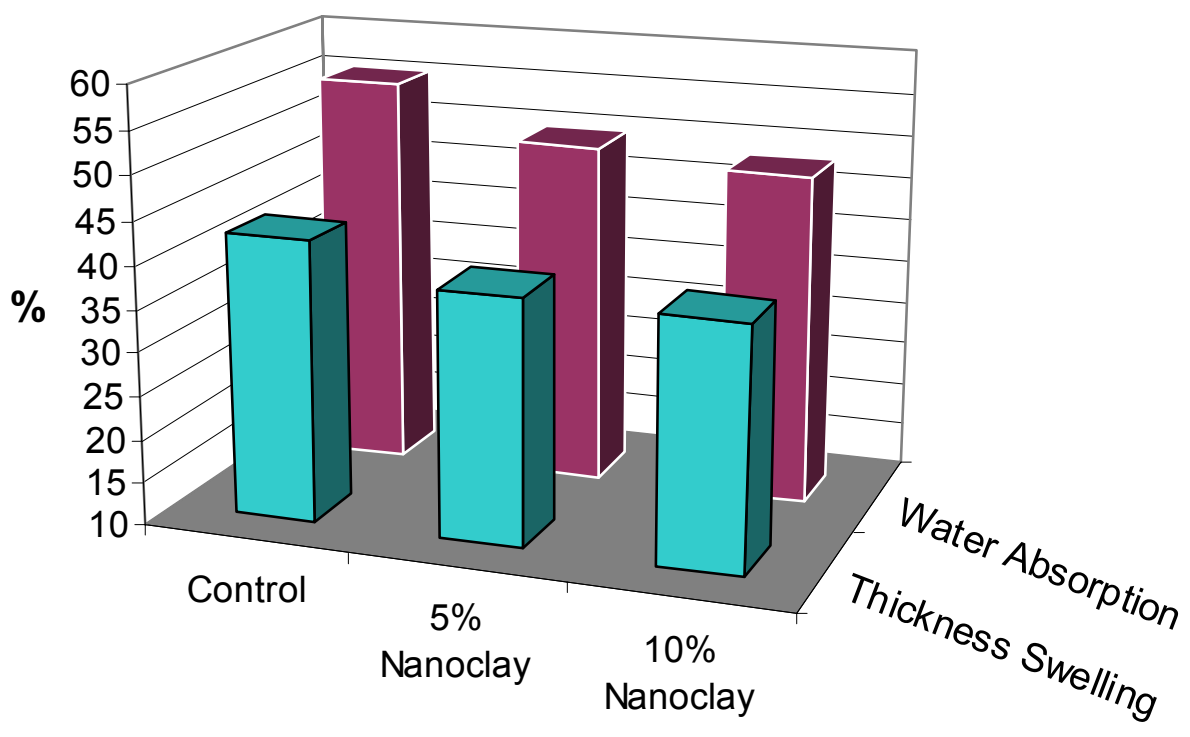

After two hours, the board samples were withdrawn from water and wiped with a paper towel to remove excess water and these results are summarized in Figure III.3. The dimensional stability of particleboards was improved by the combination UF resin and the nanoclay. It is assumed that the nanoclay with functional groups influences the formation of bonding in the composite wood product. This effect beneficially improves dimensional stability compared to the control boards.

To compare the effect of regular clay to the nanoclay, a second series of UF/Pine particle board testboards were prepared, following our standard laboratory conditions that include: press temperature of $121{ }^{\circ} \mathrm{C}$, maximum press pressure of 12,000 pounds, and a reaction time of 10 minutes. The resin content was $10 \%$ of oven dry wood mass, paraffin wax content was $1 \%$ dry wood mass and clay content was $5 \%$ of resin mass added. The 
laboratory boards were cured, then tested for thickness swelling and water absorption of particle board. These results are summarized in Figure III.4.

Figure III.4: \% Thickness Swelling Determined via ASTM Testing Protocol for PB, PB $+5 \%$ regular clay, $\mathrm{PB}+5 \%$ Nanoclay 1 (modified with Dimethyl, benzyl, hydrogenated tallow) and PB $+5 \%$ Nanoclay 2 (Methyl Dihydrogenated Tallow).

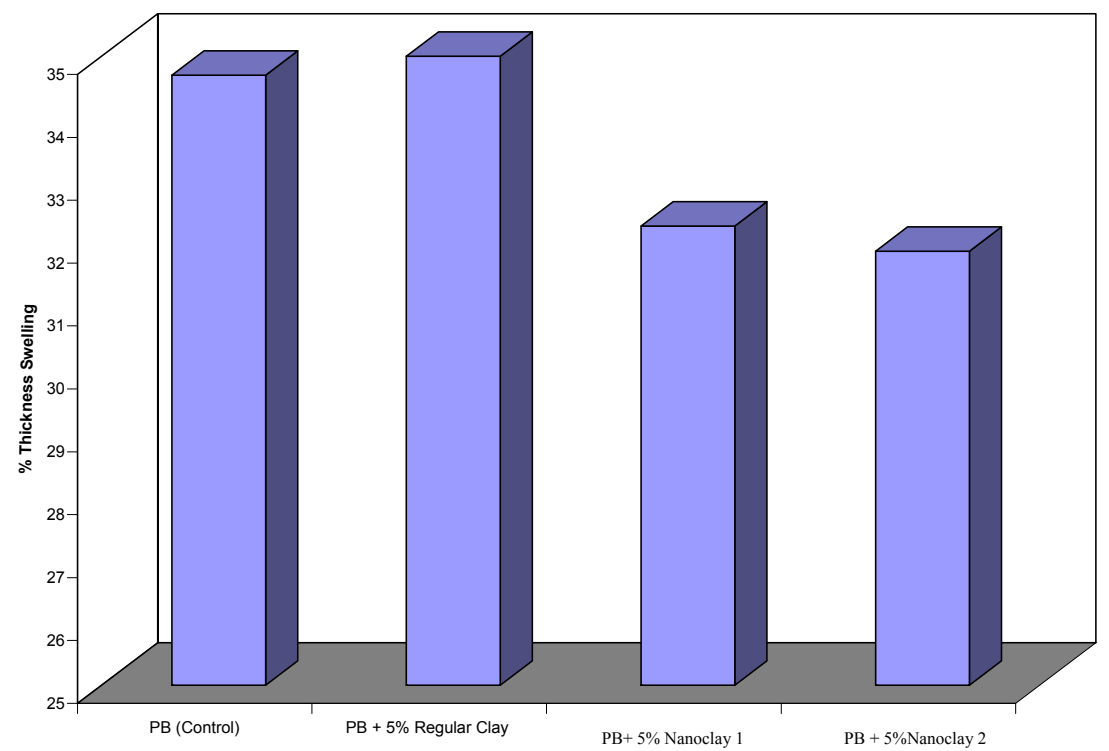

This data indicates that the nanoclays beneficially impacted thickness swelling. Finally, samples of PB were tested for IB strength properties and these are summarized in Table II.3.

Table II.3: IB Testing of Pine Particle- UF Resin Boards Prepared on Carver Press*.

\begin{tabular}{|l|c|c|}
\hline \multicolumn{1}{|c|}{ UF Board Production } & IB Density $\left(\mathrm{kg} / \mathrm{m}^{3}\right)$ & $\mathrm{IB} / \mathrm{psi}$ \\
\hline \multicolumn{1}{|c|}{ Control } & 0.707 & 54.9 \\
\hline $5 \%$ Corn Starch & 0.735 & 50.6 \\
\hline $2.5 \%$ nano clay $2 . \%$ Cationic Starch & 0.700 & 59.0 \\
\hline $2.5 \%$ Nanoclay, $2.5 \%$ Zeolite & 0.723 & 59.7 \\
\hline
\end{tabular}

Note: $* 195$ psi, $5 \min , 121{ }^{\circ} \mathrm{C}$ 
The results of the physical strength testing correlated very well with the thickness swelling and water adsorption studies. In both cases, the addition of cure additive enhanced the internal bond strength properties by approximately $5-45 \%$ depending on additive dosage and press pressures. An additional highlight of these studies is a conformation of the laboratory results we previous accomplished with the laboratory Carver press. The application of alternative cure agents or curing systems was unproductive and the remaining studies were focused on assessing the benefits of these additives to for board formation.

\section{Conclusions}

In summary, our composite board studies in this section validated the survey studies accomplished with the gel studies in section I. The results of this study support the use of low-levels of cationic starch, nanoclay, or the zeolite additives to enhance the curing properties of UF and PF resins and the final board properties. Furthermore, the trends observed with the laboratory Carver press were simulated with the larger pilot plant press. 


\section{Evaluating and Controlling the Role of Wood Extractives on Composite Board Properties}

During the formation of this proposal, several representatives from the composite board industry encouraged the researchers to evaluate the impact of wood extractives on the physical properties of composite boards manufactured with UF and PF resins. A review the literature indicates this field has been under-investigated. A patent application by Speaks et al (1999) suggests benefits by removing wood extracts with an organic solvent extraction. A recent publication by Gutowki et al. (2005) has shown that flame treatment and dichloromethane extraction improved the surface adhesion properties with PEI graft chemistry and polyurethane. Either treatment resulted in a significant increase in the wettability and $\mathrm{O}: \mathrm{C}$ ratio of the wood surface for all but the two most extractiverich wood species. Frihart (2003) has also highlighted the detrimental effects of wood extractives on the adhesion properties of epoxy resins. The detrimental effects were suggested to be due to weak boundary layer of the wood due to extractives. Interestingly, Tsukuba (1998) has presented experimental data that merbau wood extractives slightly increased the gelation rate of a phenolic adhesives. This increase in the gelation rate was revealed to be due to a fall in the resin $\mathrm{pH}$ caused by addition of the extractives.

Nonetheless, this report also documented that the main factor contributing to glue difficulty is considered to be the poor wettability of the veneer surfaces that results from the accumulation of migrating wood extractives. The effects of birch and aspen wood extractives have been shown to be detrimental to the curing of UF resins in a study by Proszyk and Stanislaw (1996). IT was proposed that the wood extractives were shown to have inhibiting effect on the hardening process of UF resin due to increasing energy of activation. These detrimental effects need also be balanced against some publications indicating that wood extractives can be used as resin component for composite board formation. For example, Tsarev (1995) has published a report titled "Use of lignin and extractives from wood as binders in the manufacture of fiberboards." This report highlights the application of tall-oil and other wood extractives as a binder for fiberboard. In light of these considerations, our research activities were directed at two key tasks:

$>$ Evaluate the effect of wood extractives on the MDF, PB and OSB boards 
Evaluate the application of select wood pretreatments to mitigate the effects of wood extractives on physical properties.

The results of these investigations are summarized in this chapter.

\section{Experimental}

\section{Materials and Chemicals.}

Softwood samples of PB, MDF, and OSB wood were acquired from commercial sources industry partners and used as received. The extractives moisture content of the pine, aspen and mixed hardwood strands was determined by Soxhlet extraction for 24 hours with 1.00:0.43 of ethanol:toluene. The extractives content of the pre-extracted MDF, PB and OSB wood was shown to $4.2 \%$.

Laccase was from Trametes villosa, the cellulase was celluclast 1.5L, xylanse was Pulpzyme and these were provided by Novozyme, Lipase was from Sigma Aldrich.

\section{Enzyme Wood Pretreatments.}

Wood samples were treated with several differing enzymatic systems including laccase, lipase, xylanase and cellulase according to literature values (Mansfield, 2003). In brief, the treatments consisted of:

The cellulase and xylanase pretreatments were accomplished with $3 \%$ by mass wood samples diluted in deionized water with a $\mathrm{pH}: 7.0$ and treatment temperature of $50{ }^{\circ} \mathrm{C}$. After mild stirring for 3 hours the water was decanted, the wood samples were air dried at room temperature and used for composite board formation. The cellulase dose was $0.50 \mathrm{gr} / \mathrm{gr}$ wood and the xylanase dosage was $0.05 \mathrm{gr} / \mathrm{gr}$ wood

$>$ The laccase and lipase pretreatments were accomplished with $3.5 \%$ by mass wood samples diluted in deionized water and $\mathrm{pH}$ adjusted to 4.7 with dilute acetic acid. After stirring for $4 \mathrm{~h}$ at $45^{\circ} \mathrm{C}$ the aqueous phase was decanted and the 
wood samples were air dried and used for composite board formation. The lipase dose was 5 units/gr wood and the laccase dosage was $0.50 \mathrm{ml} / \mathrm{gr}$ wood. The lipase 60,000 units/mg. Laccase was from Trametes villosa, and its activity was measured by monitoring the rate of oxidation of syringaldazine. One unit of activity (U) was defined as the change in absorbance at $530 \mathrm{~nm}$ of 0.001 per min per $\mathrm{mL}$ of enzyme solution, in a $100 \mathrm{mM}$ phosphate buffer $(2.2 \mathrm{~mL})$ and 0.216 $\mathrm{mM}$ syringaldazine in methanol $(0.3 \mathrm{~mL})$. The procedure was carried out at $23^{\circ} \mathrm{C}$. The activity of the laccase used in this study was $1.87 \mathrm{E}+06(\mathrm{U} / \mathrm{mL}$ of enzyme solution).

\section{Laboratory Composite Board Production.}

OSB: The wood strands were spray treated with 1\% paraffin wax and 5\% PFa resin. These treated wood strands were placed in random orientation into a $150 \times 150 \times 5 \mathrm{~mm}$ forming tray with a target board density of $0.690 \mathrm{gr} / \mathrm{cm} 3$. The samples were placed in the Carver press and 12,000 lbs pressure was applied for 3 minutes. (Note: press closing time of $30-40 \mathrm{sec})$. After the press treatment the boards were conditioned $20{ }^{\circ} \mathrm{C} 50 \%$ relative humidity for one week.

PB: The PB wood particles were spray treated with $8 \%$ UF resin. The treated wood particles were placed in a $150 \times 150 \times 5 \mathrm{~mm}$ forming tray with a target board density of $0.650 \mathrm{gr} / \mathrm{cm} 3$. The samples was placed in the Carver press and 12,000 lbs pressure was applied for 7 minutes (Note: press closing time of 30-40 sec). After the press treatment the boards were conditioned $20{ }^{\circ} \mathrm{C} 50 \%$ relative humidity for one week.

MDF: The MDF wood fibers were spray treated with and 10\% UF resin. The treated wood particles were placed in a $150 \times 150 \times 5 \mathrm{~mm}$ forming tray with a target board density of $0.650 \mathrm{gr} / \mathrm{cm} 3$. The samples was placed in the Carver press and 10,000 lbs pressure was applied for 8 minutes (Note: press closing time of 30-40 sec). After the press treatment the boards were conditioned $20{ }^{\circ} \mathrm{C} 50 \%$ relative humidity for one week. 


\section{Results and Discussion}

The effects of wood extractives on the physical properties of OSB, PB and MDF boards was initially investigated by taking commercial samples of wood used to prepare these three grades of composite boards and exhaustively Soxhlet extracting the wood furnish. The extracted wood samples were air-dried and the used to prepare laboratory OSB, PB and MDF test samples. As a control, a series of unextracted wood furnishes were employed to prepare composite boards using the same commercial wood furnish. After preparing these test samples their water adsorption and thickness swelling properties were determined following standard ASTM testing protocols (see Figure III.1). 
Figure III.1: ASTM 2 Hour Thickness Swelling and Water Absorption Properties for OSB, PD and MDF Boards Prepared with Soxhlet Extracted and Unextracted Wood Furnish

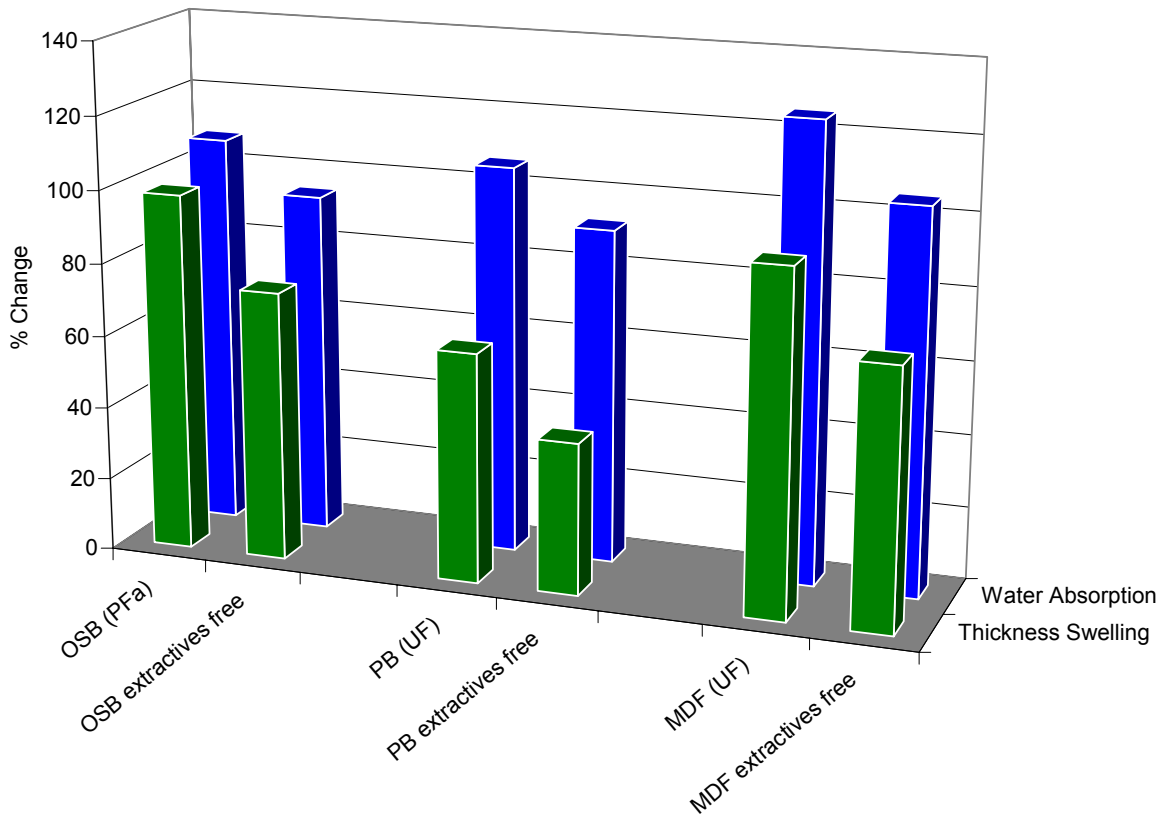

In each case, the composite boards with the wood extractives removed provided a more durable product when exposed to water for two hours. Based on this these results, our subsequent studies were directed at examining potential enzymatic treatments that could mitigate the effects of wood extractives.

Two promising biotechnological approaches to controlling wood extractives were the pretreatment of wood with laccase or lipase. Several publications have reported the ability of laccase to polymerize wood extractives. For example, Zhang, Renaud, and Paice (2005) reported that treatment of mechanical pulp with laccase at $50{ }^{\circ} \mathrm{C}$ for 2 hours decreased the lipophilic extractives present in the pulp by up to $25 \%$ and hydrophilic extractives by over $60 \%$. Furthermore, when laccase was applied to paper machine white water, lipophilic extractives were reduced by more than $50 \%$ and over $90 \%$ removal of hydrophilic extractives. Research studies by Hassingboe et al (1998) and our group (Lind et al., 2001; Chandra and Ragauskas, 2002) have documented the ability of laccase to 
polymerize and/or graft extractives and related compounds to the lignin component of wood. Finally, beyond the scope of this program several studies have documented that the pretreatment of fiber board fibers with laccase results in the formation of lignin radicals that can resulting in bonding of fibers and the minimization and/or elimination of the need for a resin (Felby et al., 2002). Clearly, the potential to polymerize and/or graft extractives to the surface of wood would be one approach at mitigating the effects of extractives on composite board properties which were documented in Figure III.1.

An alternative approach to controlling some of the effects of extractives is to employing a lipase pretreatment. This enzymatic treatment leads to the hydrolysis of triglcerides present in wood extractives (Buchert et al., 2000). Several mill trials and applications in TMP pulp mills have reported beneficial effects for lipase treatments for control strategies dealing with wood pitch deposits but it is also clear from these studies that optimal lipase effects can only be achieved through an intensive optimization studies (Mustranta, et al. 2001; Shimoto, 1999; Fleet and Breuil, 1998). Although the latter requirements were beyond the scope of these studies, we were able to successfully provide an initial assessment of these biotechnological pretreatments. This was accomplished by pretreating commercial OSB, MDF, and PB wood furnish with laccase or lipase and employing this wood for the laboratory preparation of composite board production. In addition, a series of control pretreatments were accomplished employing the same pretreatment conditions used with laccase or lipase except no enzyme was added. The results of ASTM thickness swelling and water absorption studies are summarized in Figures III.2 and III.3. 
Figure III.2: ASTM Water Absorption (WA) and Thickness Swelling (TS) for Two Hour Tests with Laboratory Prepared OSB Boards Pretreated* with Laccase or Lipase

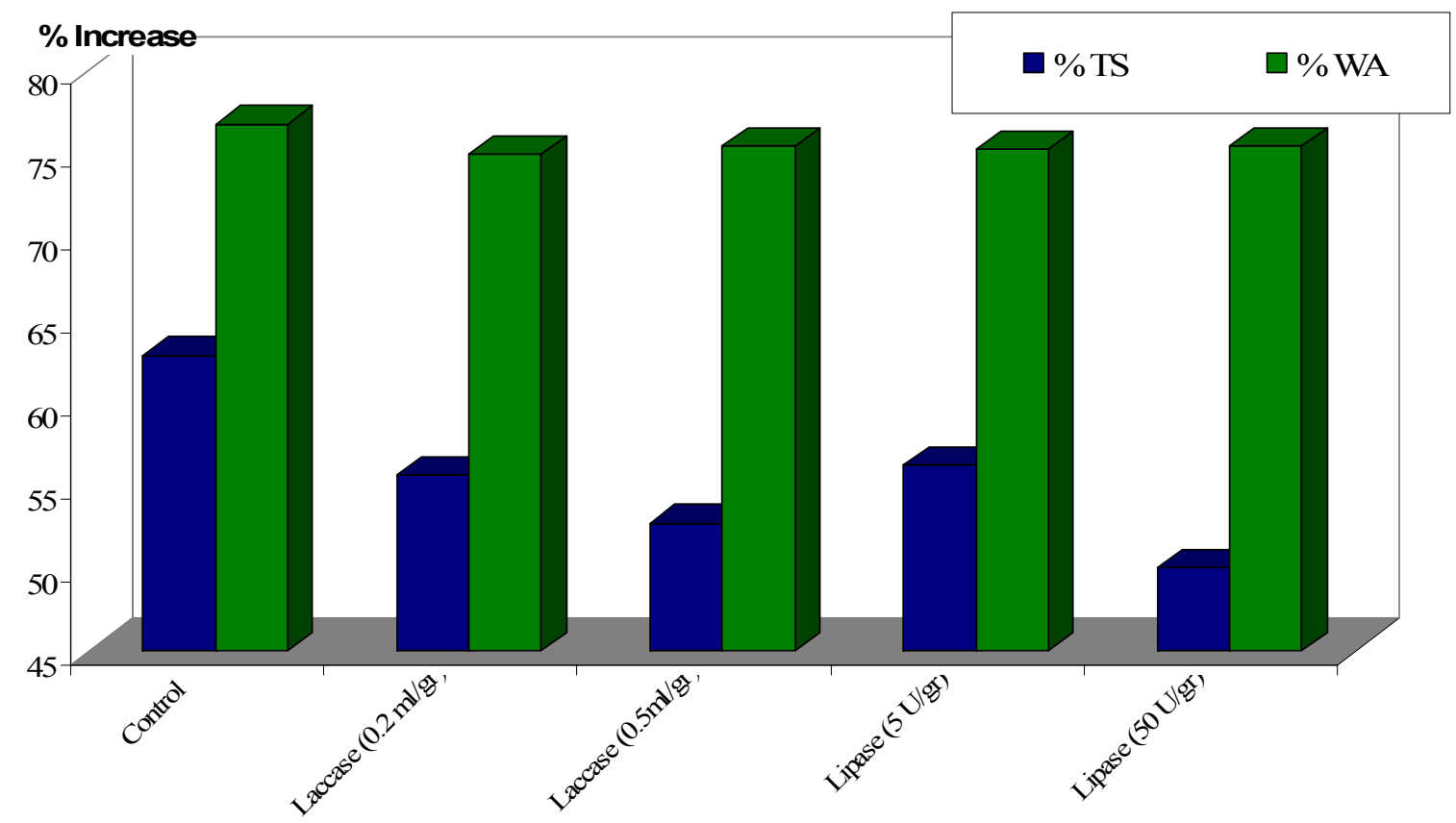

* Control: Same pretreatment conditions as enzyme treatment but no enzyme added.

The results of the OSB lipase and laccase pretreatments were clearly beneficial with respect to water stabilization properties. In terms of the control, the two hour thickness swelling properties were decreased by $10-20 \%$ whereas water absorption properties were beneficially decreased by only a few percent.

Following the same general approach MDF and PB wood furnish was treated with laccase or lipase and these samples were used, along with control samples (Note: these samples were treated in the same manner except the enzyme was omitted), to prepare a series of laboratory generated composite boards. These results are summarized in Figure III.3. 
Figure III.3: ASTM Water Absorption (WA) and Thickness Swelling (TS) for Two Hour Tests with Laboratory Prepared PB and MDF Boards Pretreated* with Laccase or Lipase

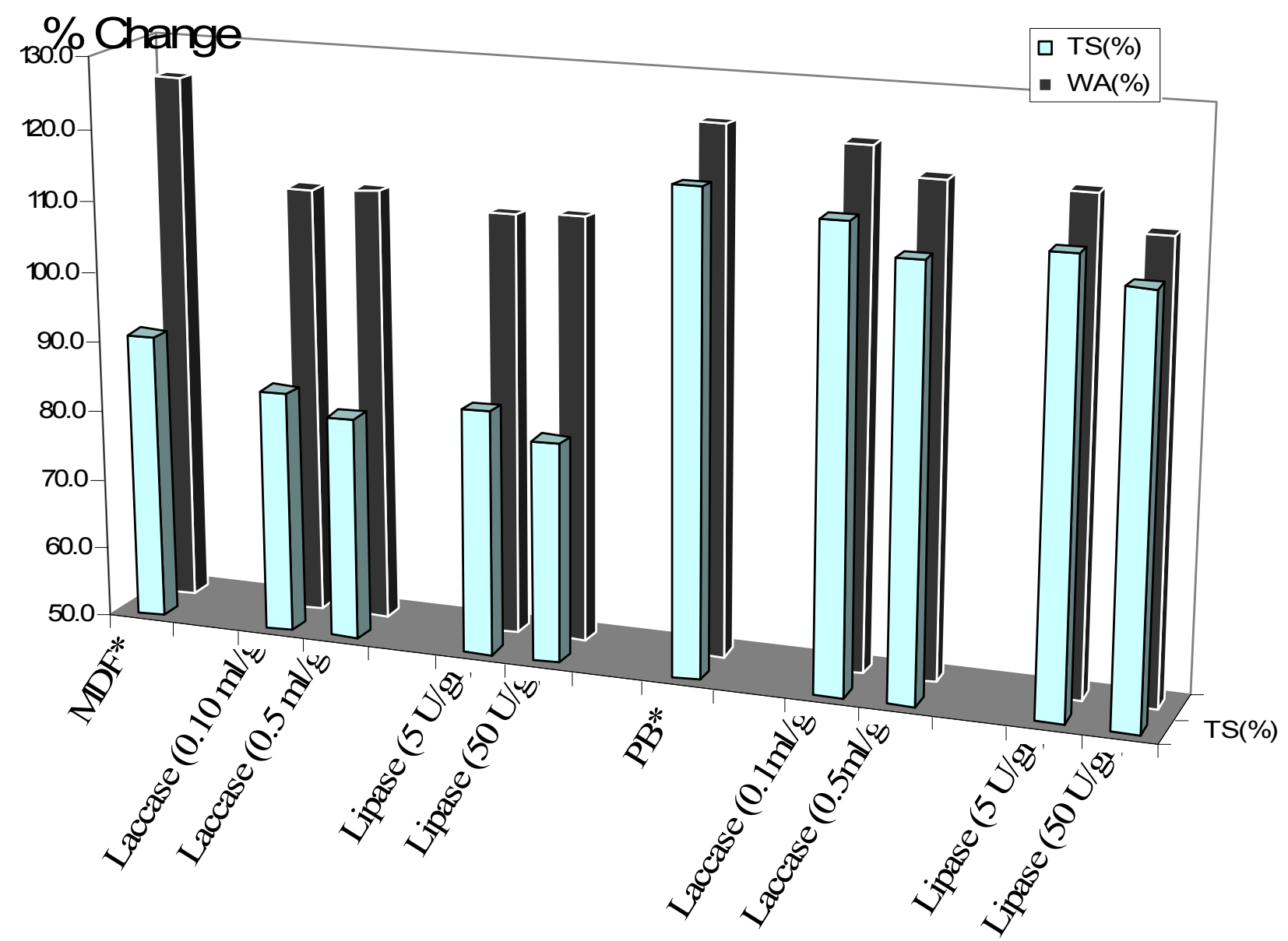

* Control: Same pretreatment conditions as enzyme treatment but no enzyme added.

This data indicated that both enzymatic treatments were beneficial to decrease both thickness swelling and water absorption for PB and MDF boards. In addition to these studies, comparable research studies were accomplished with xylanase and cellulase in an attempt to modify the surface chemistry/free-energy of the wood. These enzymatic pretreatments were not effective at changing the ASTM thickness swelling or water absorption properties of the composite board properties. Likewise, an attempt to 
polymerize wood extractives with a pretreatment of hydrogen peroxide was also shown to be ineffective.

\section{Conclusion}

The application of a laccase or lipase pretreatment of OSB, MDF, or PB wood furnish was shown to be beneficial in regards to enhancing the performance of wood composites against water. These pretreatments need to be further investigated and optimized. It is anticipated that pretreatment technologies could be readily designed whereby the enzymatic systems are applied immediately after preparing the wood furnish from the corresponding logs. This discovery provides composite board manufactures a new, green chemistry tool, to enhance the performance of the composite board products. 


\section{Characterization of PF and UF Resin Curing With and Without Additives}

\section{Introduction}

The results of investigations in chapters I and II indicate that certain additives can influence the overall cure properties of PF and UF resins. As these studies were ongoing, we also characterized the overall cure-chemistry of UF and PF resins employing advanced spectroscopic techniques. These investigations guided our additive studies and provided insight into the overall resin curing chemistry. Of the spectroscopic tools used to characterize UF and PF resins, one of the earliest was FT-IR. Early studies by Cazes (1962) and Fink (1967) demonstrated the potential of analyzing structural components of the cured resins, although instrument limitations in those days hindered detailed studies. Since these studies, the use of FT-IR has developed substantially and is employed routinely to explore a variety of chemical issues surrounding the synthesis and application of cured UF and PF resins. For example, Carotenuto and Nicolais (1999) followed the kinetics of PF curing and Poljansek and Krajnc (2005) have reported the use of quantitative FT- IR spectroscopy to characterize phenol - formaldehyde prepolymer resins. Advances in the use FT-IR UF resins has also progressed substantially and is now being examined as an on-line analytical technique (Poljansek et al., 2006).

The use of NMR provides a complimentary tool to FT-IR to characterize the curing of UF and PF resins. The early stages of curing have been studied by liquid phase 13C NMR and the polymerized material by 13C CP/MAS NMR. For example, Park and Riedl (2000) recently reported the application of liquids and solid-state 13C-NMR to investigate the cure-acceleration effects of propylene carbonate, potassium carbonate and sodium carbonate. The liquid-phase studies indicated that the cure-acceleration mechanism with propylene carbonate/PF resin was caused by an increased reactivity of the phenol rings, while the addition of potassium or sodium carbonate resulted in the presence of ortho-ortho methylene linkages. 


\section{Experimental}

\section{Resin Curing Studies}

Samples of UF, PFa, and PFb resin were cured in glass vials according to experimental conditions summarized in Table IV.1.

Table IV.1: Experimental Curing Conditions.

\begin{tabular}{|l|l|l|}
\hline Resin & Curing Temperature $/{ }^{\circ} \mathrm{C}$ & Curing Time $/ \mathrm{min}$. \\
\hline $\mathrm{PFa}$ & 175 & $0.5,1.0,2.0,4.0,8.0$ \\
\hline $\mathrm{PFb}$ & 175 & $0.5,1.0,2.0,4.0,8.0$ \\
\hline $\mathrm{UF}$ & 150 & $0.5,1.0,2.0,4.0,8.0$ \\
\hline Samples were stored at $0{ }^{\circ} \mathrm{C}$ prior to analysis \\
\hline
\end{tabular}

The cured resins were subsequently analyzed by FT-IR and ${ }^{13} \mathrm{C}$ CPMAS NMR.

\section{FT-IR Resin Studies.}

FT-IR studies were accomplished using a Nicolet 5 SXC spectrometer in the transmittance mode. Each sample was analyzed by placing $2 \mathrm{mg}$ of cured resin in $\mathrm{KBr}$ powder $(0.4 \mathrm{gr})$ and then preparing a KBr-IR pellet. All spectra were recorded at $24^{\circ} \mathrm{C}$. Typically, this procedure yielded spectral data that could be reproducibly acquired with $<$ $2 \%$ deviations in relative peak ratios.

\section{CP/MAS ${ }^{13}$ C NMR Resin Studies}

The solid-state $\mathrm{CP} / \mathrm{MAS}{ }^{13} \mathrm{C}$ NMR experiments were performed on a Bruker Avance-400 spectrometer operating at frequencies of $100.59 \mathrm{MHz}$ for ${ }^{13} \mathrm{C}$. All the experiments were carried out at ambient temperature using a Bruker 4-mm MAS probe. The samples were packed in $4 \mathrm{~mm} \mathrm{ZrO}$ rotors and spun at $5 \mathrm{kHz},{ }^{13} \mathrm{C} \mathrm{CP} / \mathrm{MAS}$ data were acquired following literature methods with $~ 8000$ scans accumulated/sample. (Pu et al., 2006) 
Glycine was used for the Hartman-Hahn matching calibration procedures and as an external standard for the calibration of the chemical shift with the maximum intensity of the carbonyl carbon resonance assigned to $176.0 \mathrm{ppm}$.

\section{DSC Resin Studies}

Heat analysis of resins was carried out in a Perkin-Elmer Pyris 1 DSC. Resin samples (20 mg) were prepared in Perkin-Elmer large volume capsules which were sealed with Vitron O-rings that can withstand 1.4-2.2 Mpa. The sealed capsules were transferred to the DSC for analysis with a heating rate of $10{ }^{\circ} \mathrm{C} / \mathrm{min}$ from $30{ }^{\circ}$ to $200{ }^{\circ} \mathrm{C}$.

\section{Results and Discussion}

An initial evaluation of curing of the three reference resins was accomplished by curing the resins as described in Table IV.1 and characterizing the product by FT-IR spectroscopy. These results are summarized in Figures IV. 1 - .3.

Figure IV.1: $\quad$ FT-IR analysis of PFa resin cured at $175{ }^{\circ} \mathrm{C}$ for $0.50,1,2$, 4, and 8 minutes.

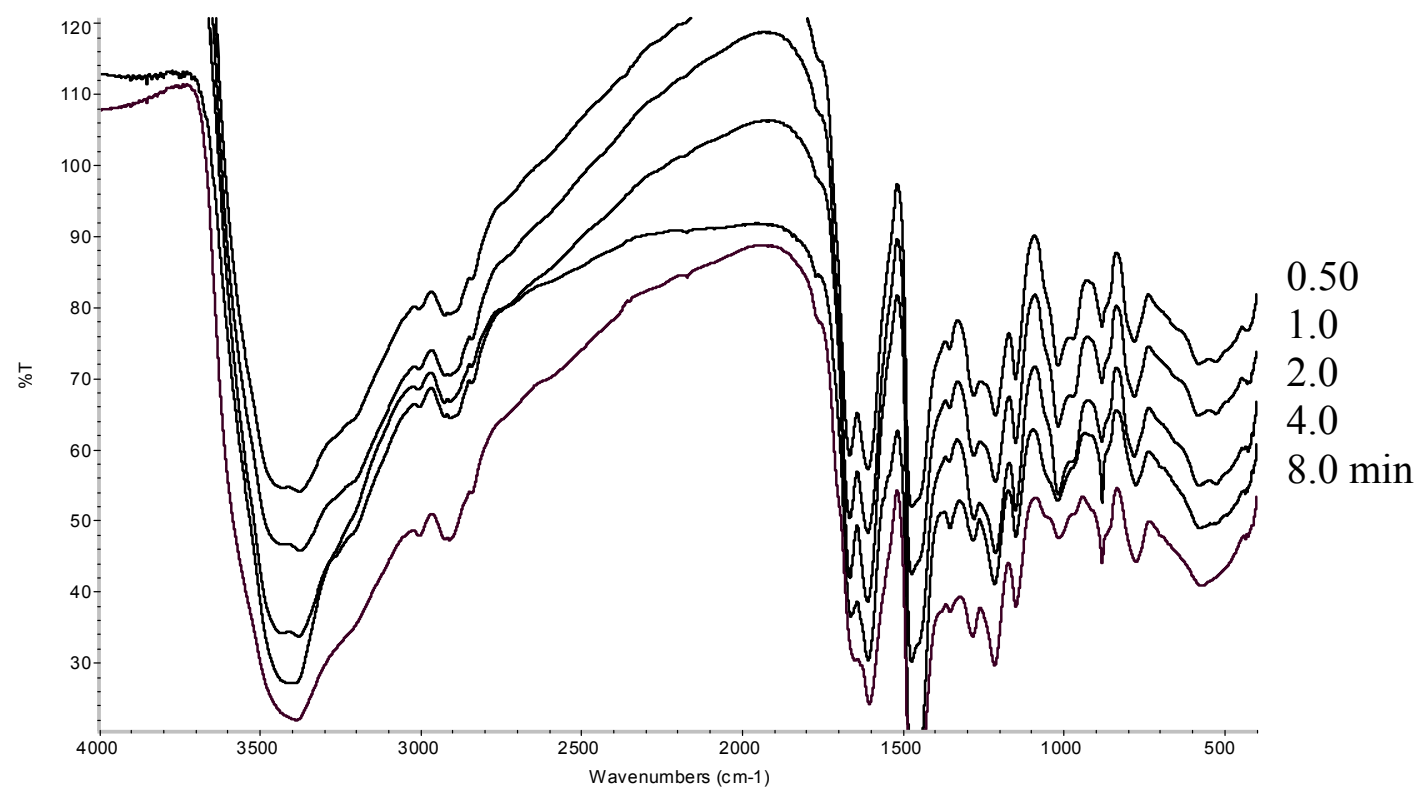


Figure IV.2: $\quad$ FT-IR analysis of $\mathrm{PFb}$ resin cured at $175^{\circ} \mathrm{C}$ for $0.50,1,2,4$, and 8 minutes.

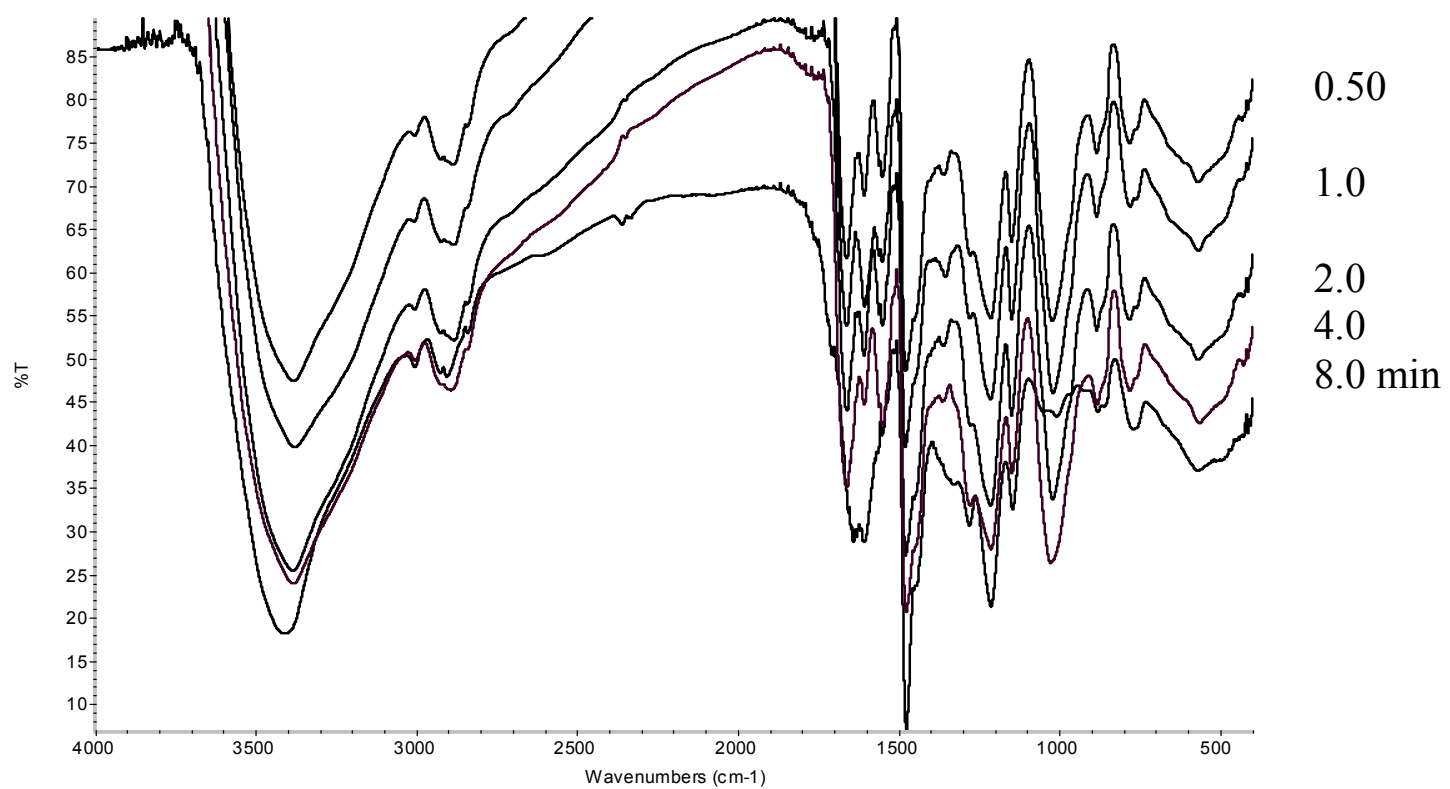

Figure IV.3: FT-IR analysis of UF resin cured at $150{ }^{\circ} \mathrm{C}$ for 2,4 , and 8 minutes.

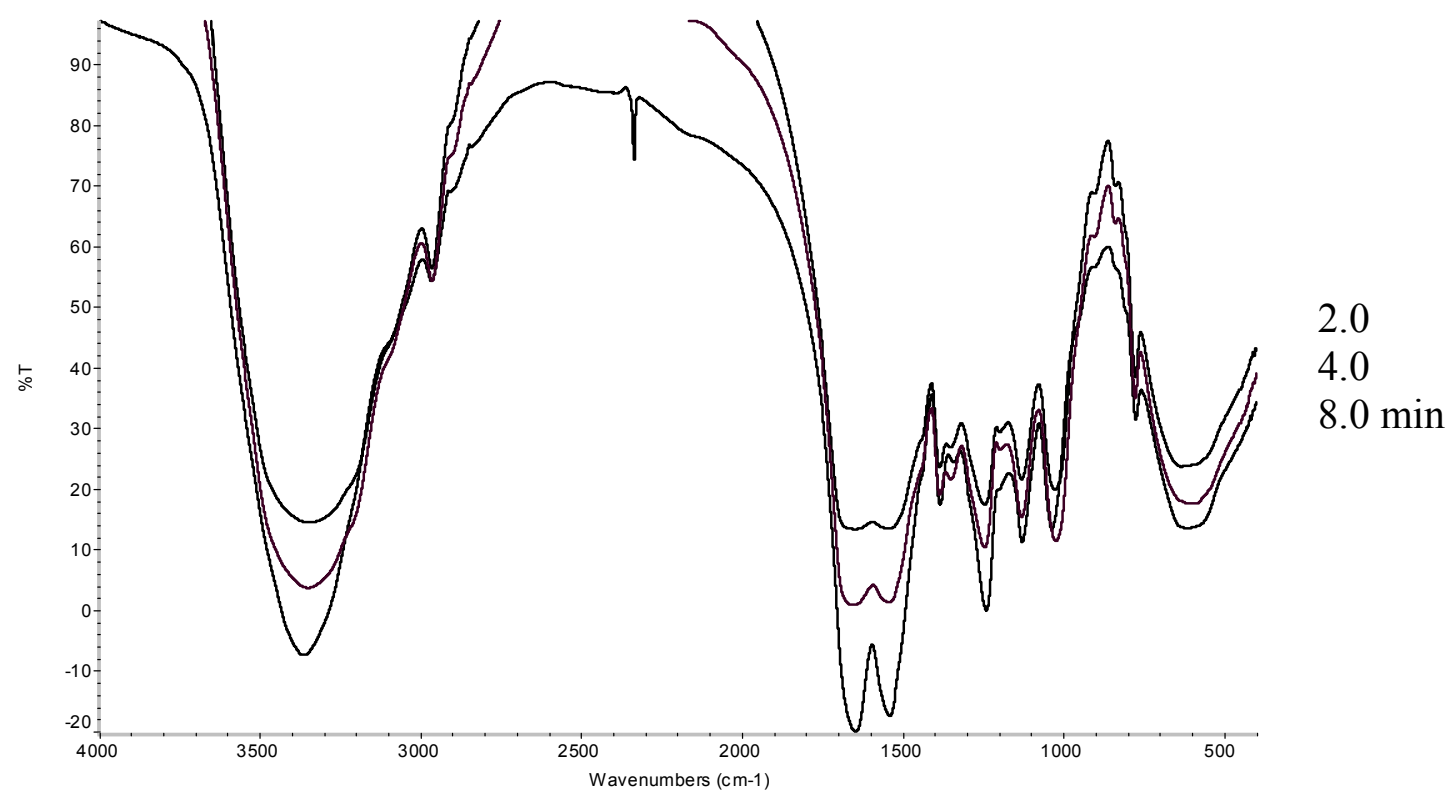

The primary signal assignments for PF and UF resins are summarized in Table IV.2. 
Table IV.2: Absorption Assignments for Cured PF (Carotenuto, 1999) and UF (Jada, 1988) Resins

$\begin{array}{llll}\begin{array}{l}\text { PF Functional } \\ \text { Group }\end{array} & \text { Absorption } / \mathrm{cm}^{-1} & \begin{array}{l}\text { UF Functional } \\ \text { Group }\end{array} & \text { Absorption } / \mathrm{cm}^{-1} \\ \mathrm{H}-\mathrm{O}- & & -\mathrm{NH}_{2} & \\ \mathrm{Ar}-\mathrm{H} & 3330,1359 & -\mathrm{NHY} & 3430 \\ -\mathrm{CH}_{2}- & 3100 & -\mathrm{CH} & 3320 \\ \mathrm{C}-\mathrm{C} & 2900,1450 & \text { amide } & 2980 \\ & 1612,1598 & & 1655 \\ \mathrm{Ar}-\mathrm{O}- & 1480 & & \\ \mathrm{CH}_{2}-\mathrm{OH} & 1200 & & \end{array}$

The IR spectra of UF resins can be characterized to two strong bands at near 1500 and $1650 \mathrm{~cm}-1$, which can be assigned to amide II and amide I, respectively. Also, the weak bands at near $1350 \mathrm{~cm}-1$ appear in this IR spectra. According to the literature the absorption band at $1300 \mathrm{~cm}-1$ can be ascribed to the formation of methyol group during the curing of UF resin. The data in our studied possess a band of medium intensity near $1020 \mathrm{~cm}-1$. Also, two more medium intensity bands at the range $1130-1250 \mathrm{~cm}-1$ can be found in this IR analysis of UF resin. During the curing, the infrared spectra change significantly after 8 minutes. The bands at 1500-1650cm-1 are separated distinctly. $1350 \mathrm{~cm}-1$ band become more distinct and decrease slightly as methyol group decreases in condensation reaction of UF resins.

IR spectra of PF resins exhibit a very strong band at near 3,500cm-1, and separated bands at 1500-1700 cm-1, and a strong intensity of band at $1470 \mathrm{~cm}-1$. Also, two medium intensity bands at near 1210 and $1020 \mathrm{~cm}-1$ can be found below $1300 \mathrm{~cm}-1$ of wave number including 3-4 small bands. In comparison to $\mathrm{PFa}$, the difference of $\mathrm{PFb}$ resins is one more separated band in $1550-1650 \mathrm{~cm}-1$ which may be caused by different $\mathrm{P} / \mathrm{F}$ ratio. Also, the PFb absorption near 1210 and $1020 \mathrm{~cm}-1$ is more distinct and larger than PFa suggesting differences in curing chemistry.

It is generally known that the IR spectra of PF resins exhibit adsorption because of the $\mathrm{OH}, \mathrm{CO}$, and phenyl ring structures. According to Table IV.2, the IR frequency of the PF 
resins shows a broad band in the region of 3000-3500 cm-1 which can be attributed to the result of the intra- and intermolecular hydrogen bonded phenolic $\mathrm{OH}$ stretching vibrations. The strong peaks at $1500-1600 \mathrm{~cm}-1$ may attributed to the $\mathrm{C}=\mathrm{C}$ stretching vibration of aromatic ring. The bands at $1470 \mathrm{~cm}-1$ may also be attributed to $\mathrm{C}=\mathrm{C}$ aromatic skeletal vibration. On the other hand, Vasishth (1975) reported that PF can be characterized by IR adsorption at 1010, 1050 and $1230 \mathrm{~cm}-1$ due to the presence of benzyl ether linkages.

During the curing of PF resins, bands in 1500-1700 cm-1 are changed markedly together with bands of near 1010 and $1200 \mathrm{~cm}-1$. The absorption bands at 1500-1700 cm-1 appear to be decreased in intensity and then combine. These IR absorptions for PFb begin to disappear and combine after 4 minutes of curing. The bands at near $1010 \mathrm{~cm}-1$ also decreased. On the other hand, the band at near $1200 \mathrm{~cm}-1$ become more distinct and increases slightly when curing time is increased. It is interpreted that changes of IR bands could be related to the formation cross-linking structure between phenol and formaldehyde.

Following this analysis the chemistry of the additive UF and PF resins were characterized by FT-IR spectroscopy as summarized in Figures IV.4 - .6. Since each of these additiveresin systems cured at differing rates it was decided to cure each to their gel point at 100 ${ }^{\circ} \mathrm{C}$. 
Figure IV.4: FT-IR analysis of PFa Resin Cured to Gel Point at $100{ }^{\circ} \mathrm{C}$ with $2 \%$ Cationic Starch, Zeolite, Nanoclay (Based on Resin Solid Content) and Control (No additive)

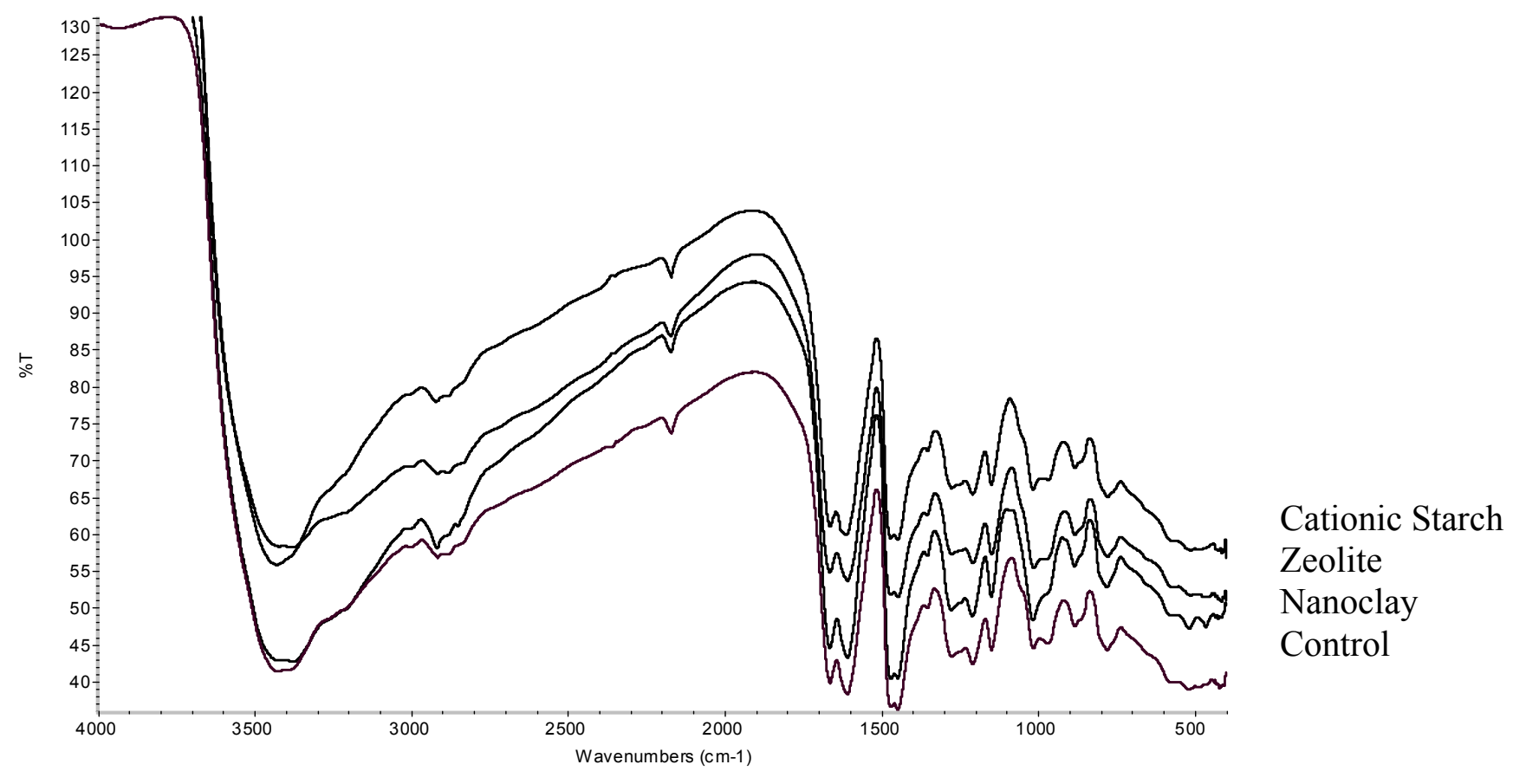

Figure IV.5: FT-IR analysis of PFb Resin Cured to Gel Point at $100{ }^{\circ} \mathrm{C}$ with $2 \%$ Cationic Starch, Zeolite, Nanoclay (Based on Resin Solid Content) and Control (No additive)

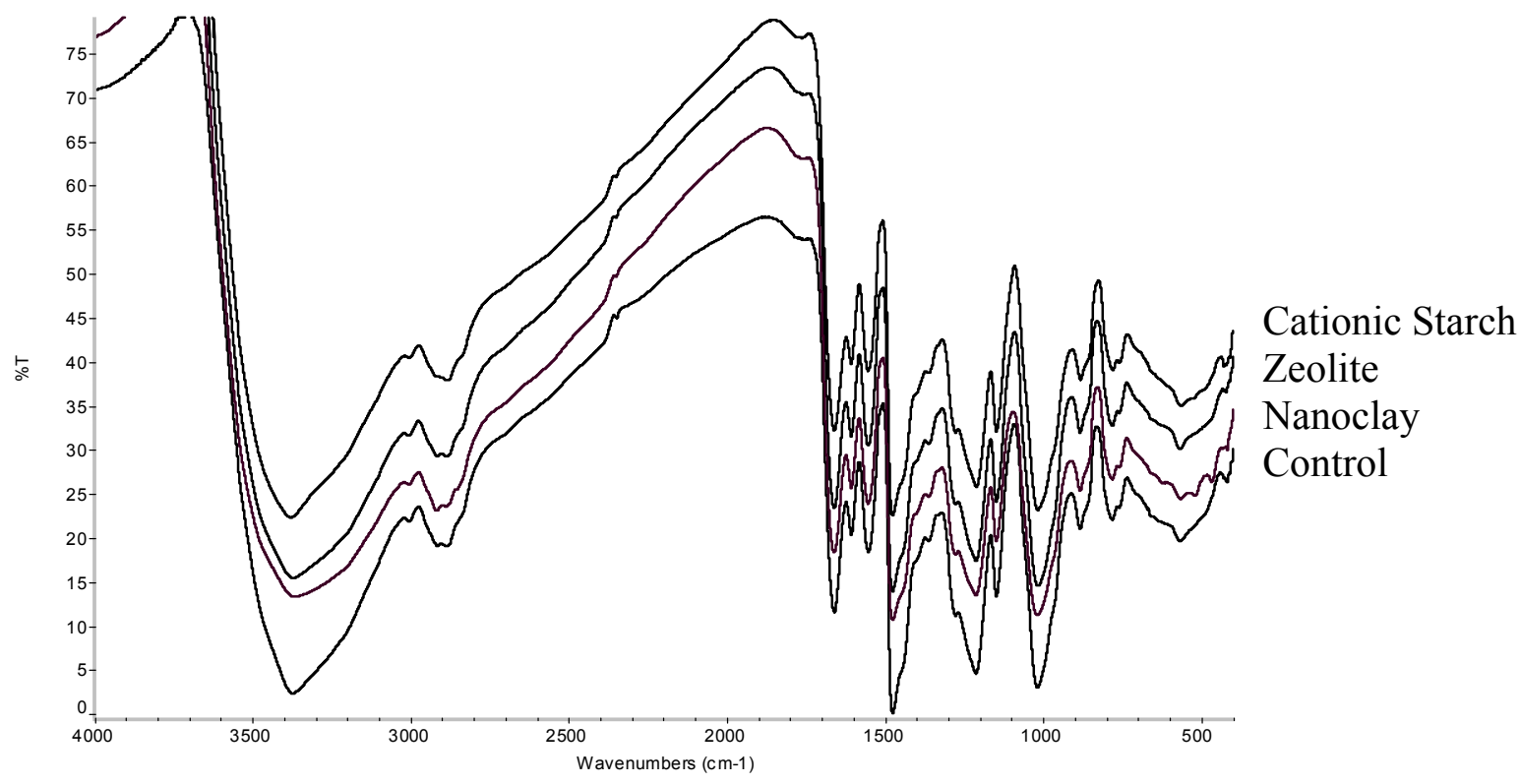


Figure IV.6: FT-IR analysis of UF Resin Cured to Gel Point at $100{ }^{\circ} \mathrm{C}$ with $2 \%$ Cationic Starch, Zeolite, Nanoclay (Based on Resin Solid Content) and Control (No additive)

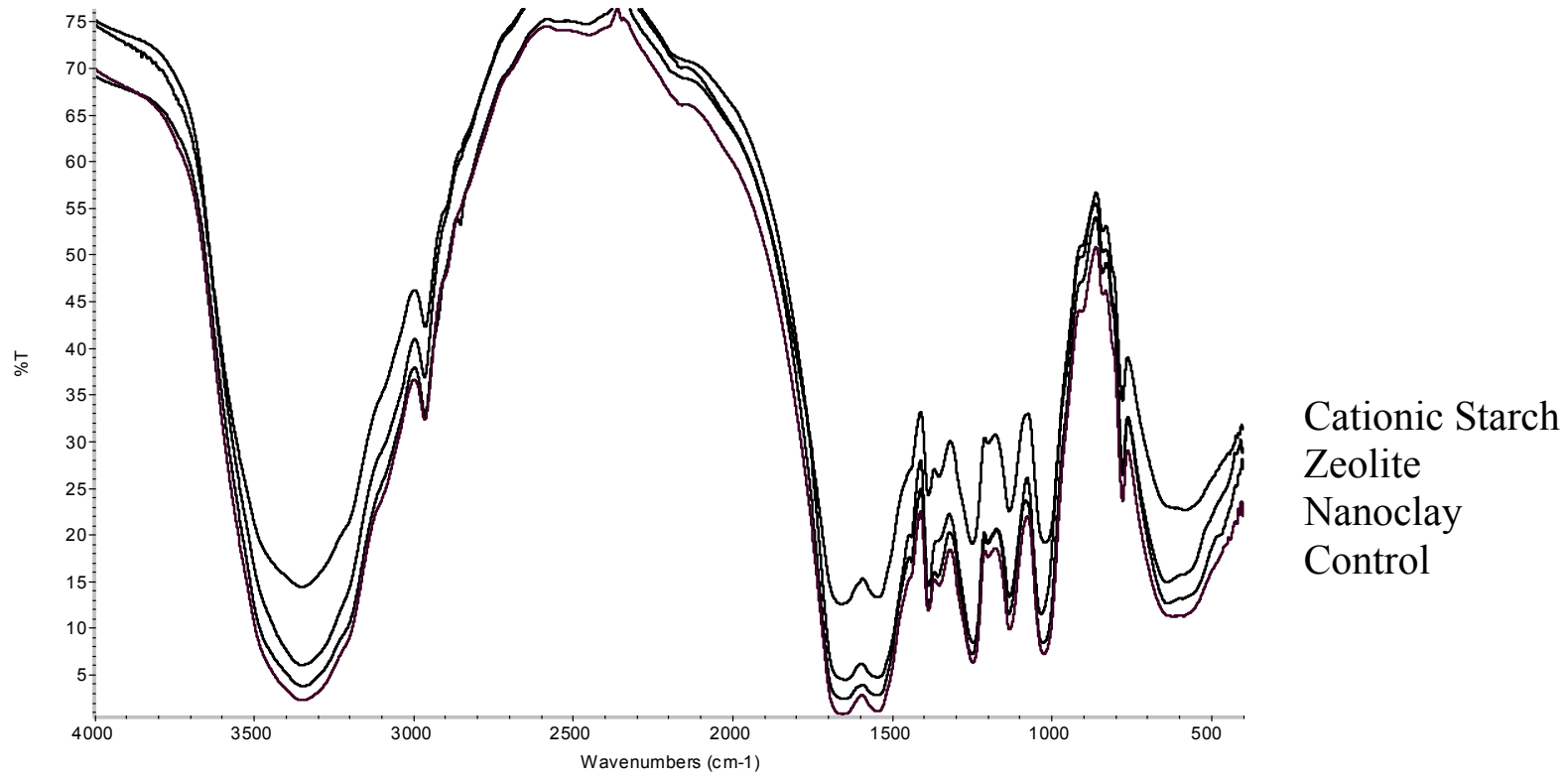

FT-IR analysis of the resins cured with and without cure additives to gelation indicate no significantly large difference has occurred with the gelled resins. However, the UF FT-IR data for the additive enriched samples indicates that the absorption band near $1350 \mathrm{~cm}^{-1}$ has became slightly weaker. It is known that band near $1300 \mathrm{~cm}-1$ is due to methyol containing compounds. Therefore, a decreased band in this region is likely related to the variation of methyol group content. Since the samples in Figures IV.4 to .6 were prepared at differing gel times, a second series of experiments were preformed employing a standard time 
Figure IV.7: $\quad$ FT-IR analysis of PFa Resin Cured at $100{ }^{\circ} \mathrm{C}$ for 30 min. with $2 \%$ Cationic Starch, Zeolite, Nanoclay (Based on Resin Solid Content) and Control (No additive)

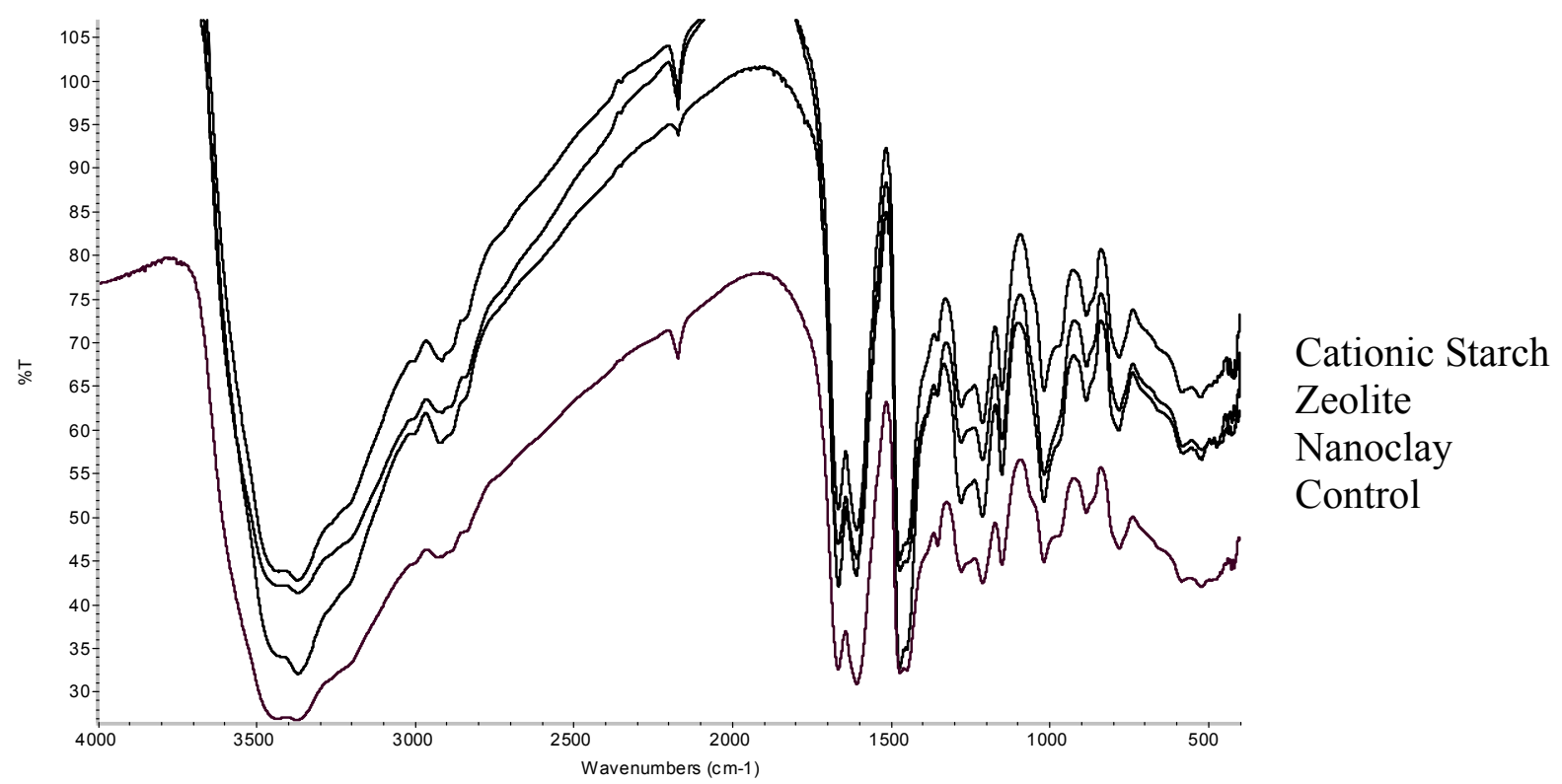

Figure IV.8: FT-IR analysis of PFb Resin Cured at $100{ }^{\circ} \mathrm{C}$ for 30 min. with $2 \%$ Cationic Starch, Zeolite, Nanoclay (Based on Resin Solid Content) and Control (No additive)

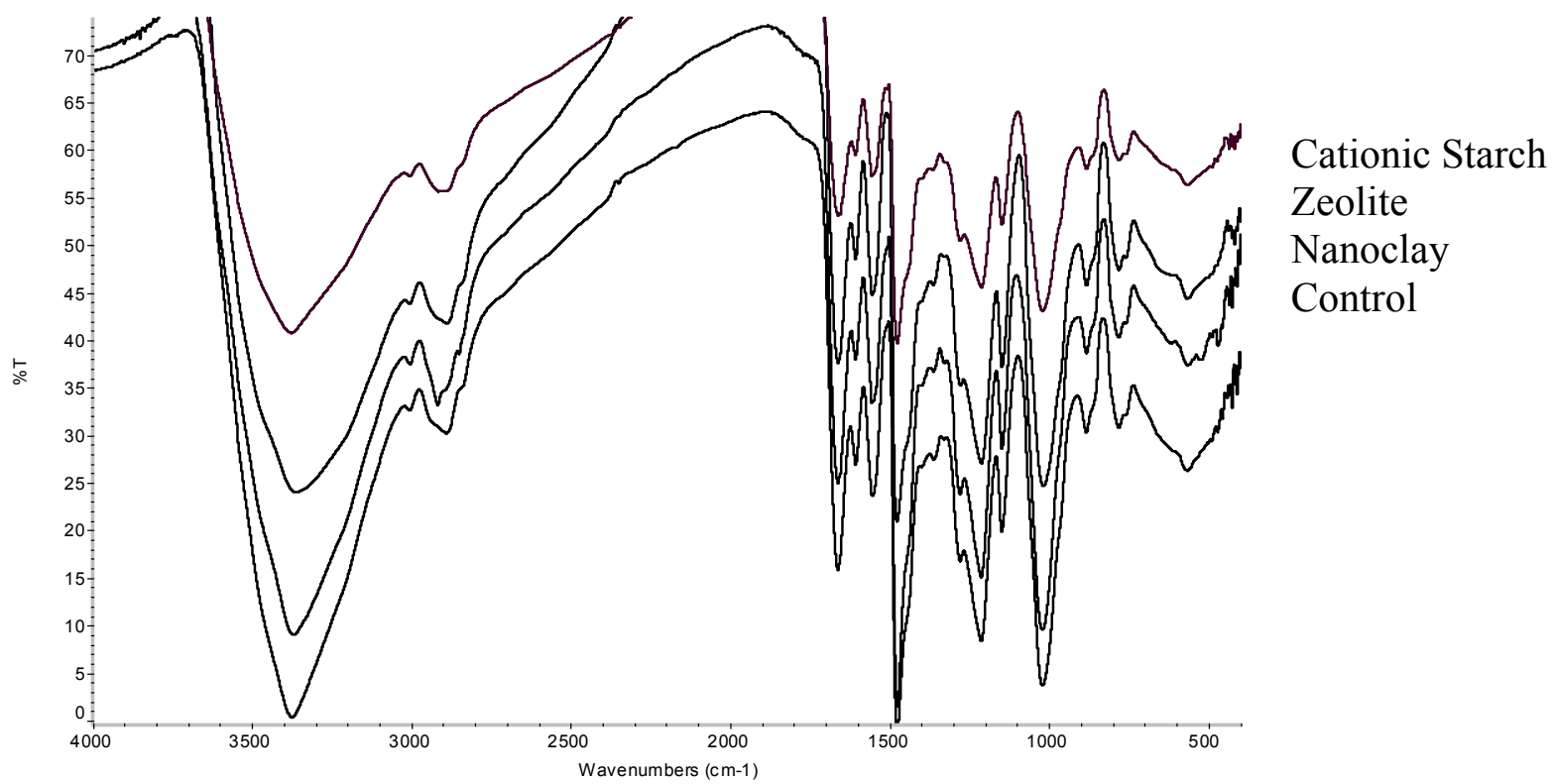


Figure IV.9: $\quad$ FT-IR analysis of UF Resin Cured at $100{ }^{\circ} \mathrm{C}$ for $30 \mathrm{~min}$. with $2 \%$ Cationic Starch, Zeolite, Nanoclay (Based on Resin Solid Content) and Control (No additive)

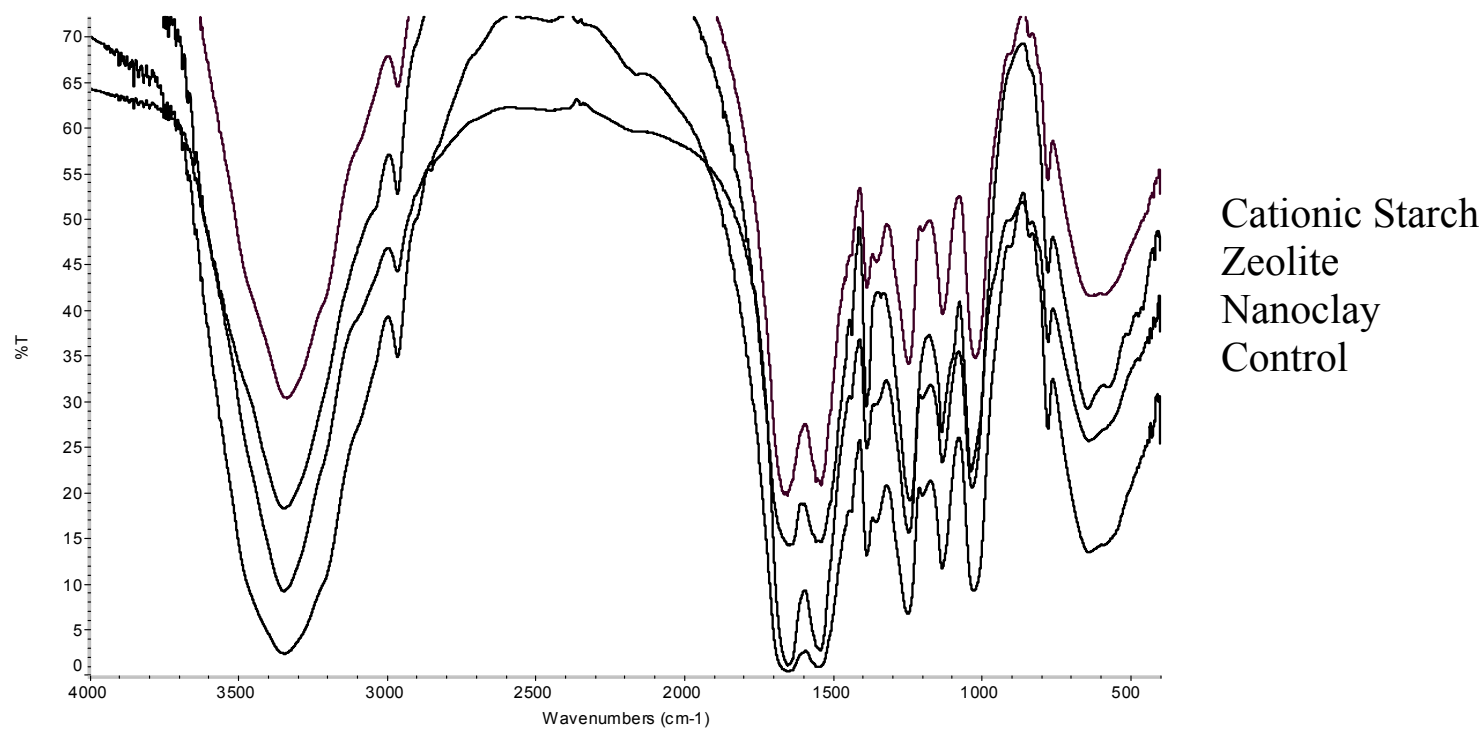

In contrast to the PF and UF resins cured to gelation, resins cured for 30 minutes did indict some differences in the IR spectra with the incorporation of additives. In UF resins, the bands at 1500-1650 cm-1 are separated distinctly with addition of additives. Also, the addition of additives to the UF resin leads to slightly change the peak near $1350 \mathrm{~cm}-1$. When zeolite $\mathrm{Y}$ was added to UF resin, the band in this region disappeared.

For the PFa resin, the addition of the additives lead to a slight increase in the peak at $1470 \mathrm{~cm}-1$ which may be assigned to $\mathrm{C}=\mathrm{C}$ aromatic skeletal vibrations. But overall, the control and additive enriched PF resins appeared to be very similar in regards to the IR spectra data. These results were viewed in a very positive vein as it suggested that if the polymerization has not significantly changed the physical properties should be comparable which supports the observations reported in chapters I and II.

To further explore the curing chemistry of the UF and PFa resin, samples were heated to $100{ }^{\circ} \mathrm{C}$ for periods of 32,64 , and 128 minutes. Figures IV.10 and .11 present typical spectral data acquired for these samples. 
Figure IV.10: ${ }^{13} \mathrm{C} C \mathrm{CP} / \mathrm{MAS}$ NMR analysis of PFa resin cured for 64 minutes at $100{ }^{\circ} \mathrm{C}$.

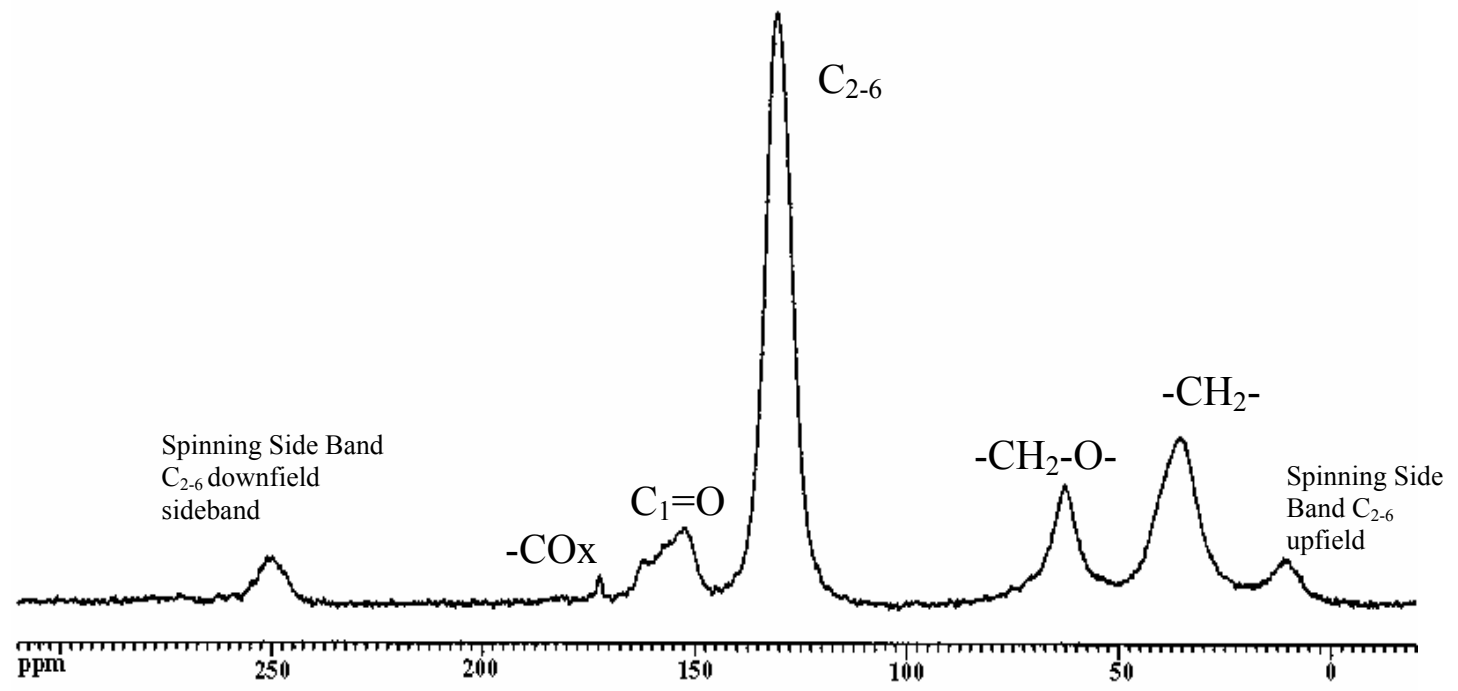

Figure IV.11: ${ }^{13} \mathrm{C} C$ P/MAS NMR analysis of UF resin cured for 64 minutes at $100{ }^{\circ} \mathrm{C}$.

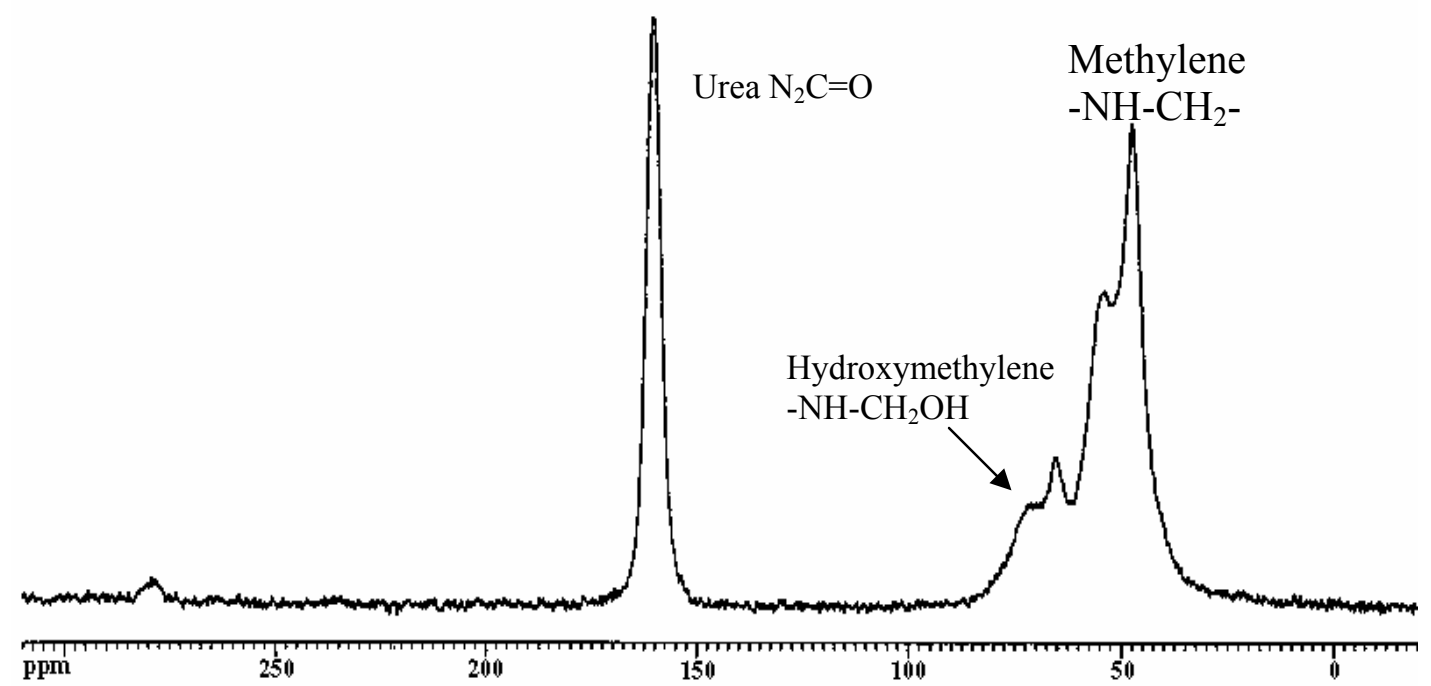

The NMR techniques facilitated monitoring changes in the resin structure during curing. Figure IV.12 summarizes the changes methylene versus methylol groups as a function of curing. 
Figure IV.12: ${ }^{13} \mathrm{C} \mathrm{CP/MAS} \mathrm{NMR} \mathrm{analysis} \mathrm{of} \mathrm{Methylene} \mathrm{(-CH2-):Phenol} \mathrm{(P)} \mathrm{and}$ Methyol (-CH2-OH):Phenol (P) Groups in PFa resin cured for $32-128$ minutes at 100 ${ }^{\circ} \mathrm{C}$.

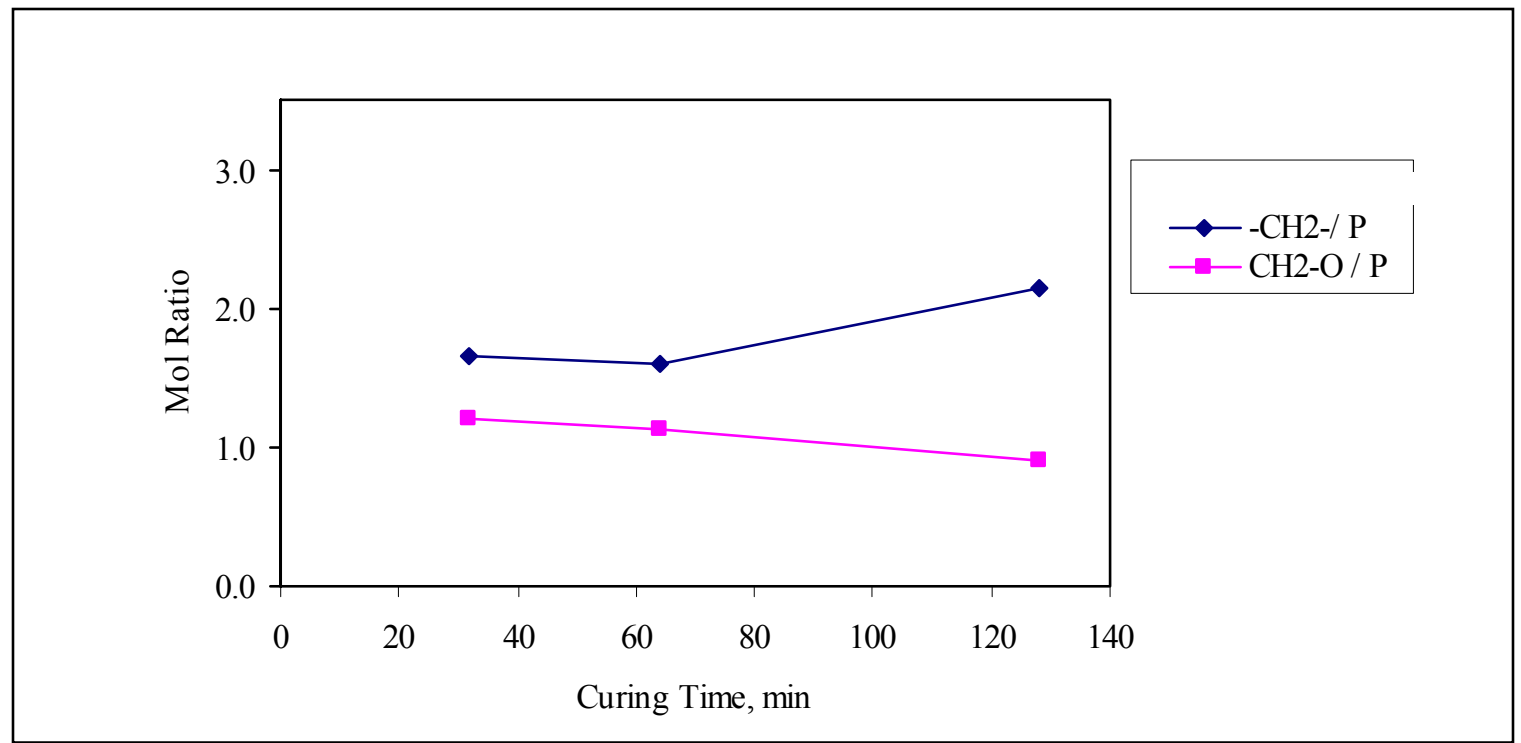

Since resin formation involves the loss of water these values are consistent with the overall cure process. An examination of the $-\mathrm{CH}_{2}-$ :Phenol and $-\mathrm{CH}_{2}-\mathrm{OH}:$ Phenol trends for Figure IV.13 were comparable to the data in Figure IV.12, although the slope was reduced. The results summarized in Figure IV.14 indicate that both resins have carbonates present in the beginning and this increased during curing. The increase in carbonates was attributed to absorption of carbon dioxide from the air. 
Figure IV.13: ${ }^{13} \mathrm{C} \mathrm{CP} / \mathrm{MAS}$ NMR analysis of Methylene (-CH2-):Phenol (P), and Methyol (-CH2-OH): Phenol (P) in PFb resin cured for $32-128$ minutes at $100{ }^{\circ} \mathrm{C}$.

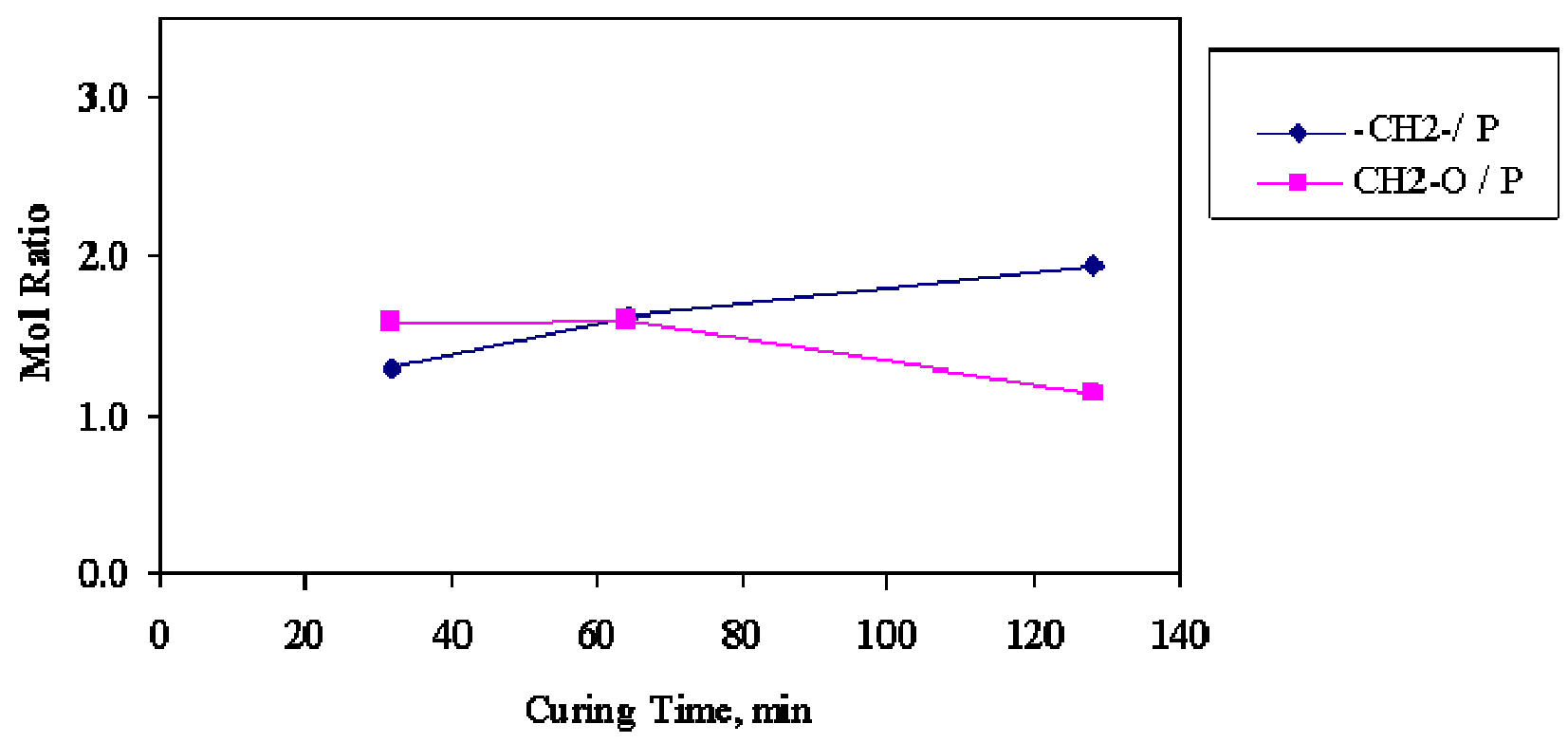


Figure IV.14: ${ }^{13} \mathrm{C} \mathrm{CP/MAS} \mathrm{NMR} \mathrm{analysis} \mathrm{of} \mathrm{CO}_{\mathrm{x}}$ for $\mathrm{PFa}$ and $\mathrm{Pfb}$ resin cured for 32 128 minutes at $100{ }^{\circ} \mathrm{C}$.

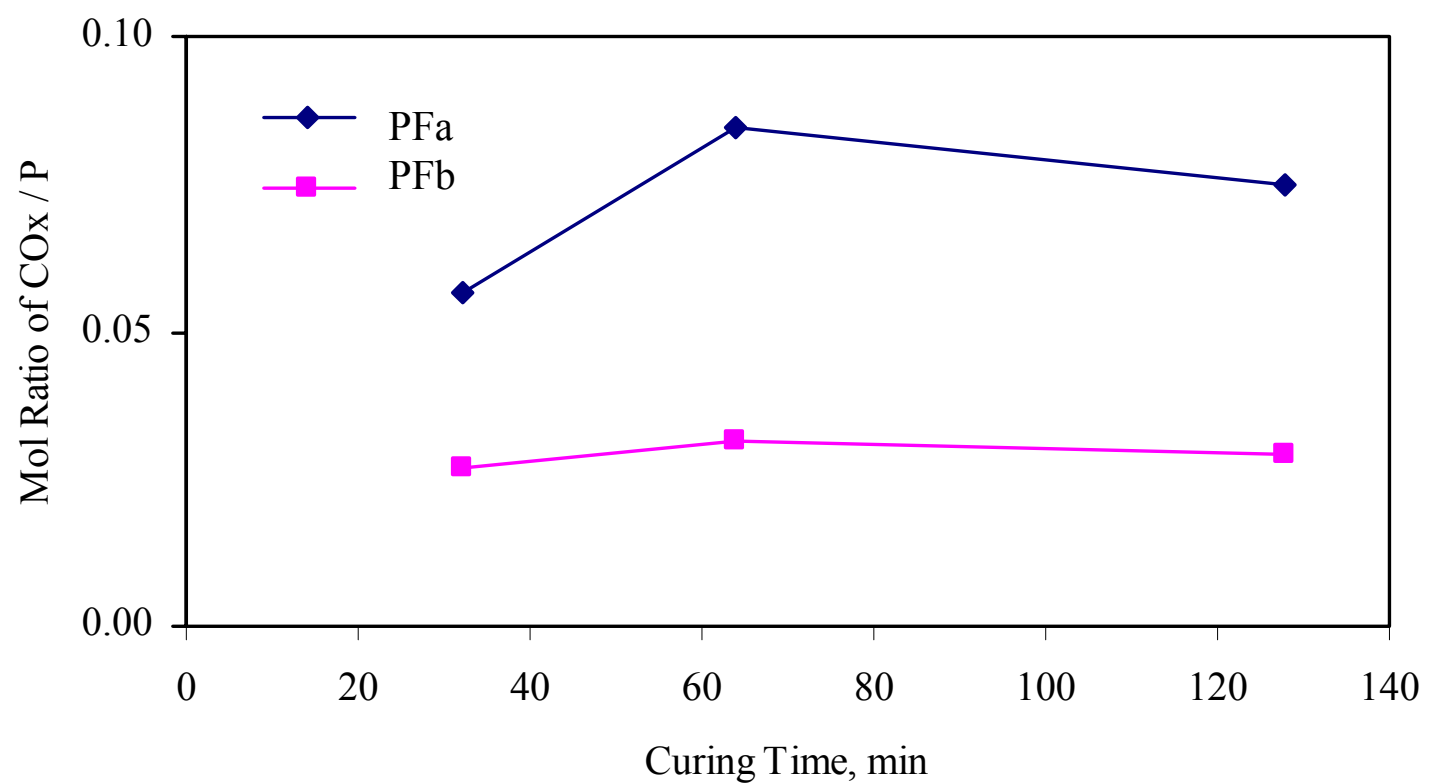

Figure IV.15: ${ }^{13} \mathrm{C}$ CP/MAS NMR analysis of UF cured for $32-128$ minutes at $100{ }^{\circ} \mathrm{C}$. Signal intensity of Urea:Phenol (U:P), Methylene (-CH2-):Urea; and Methylol (-CH2$\mathrm{OH})$ :Urea.

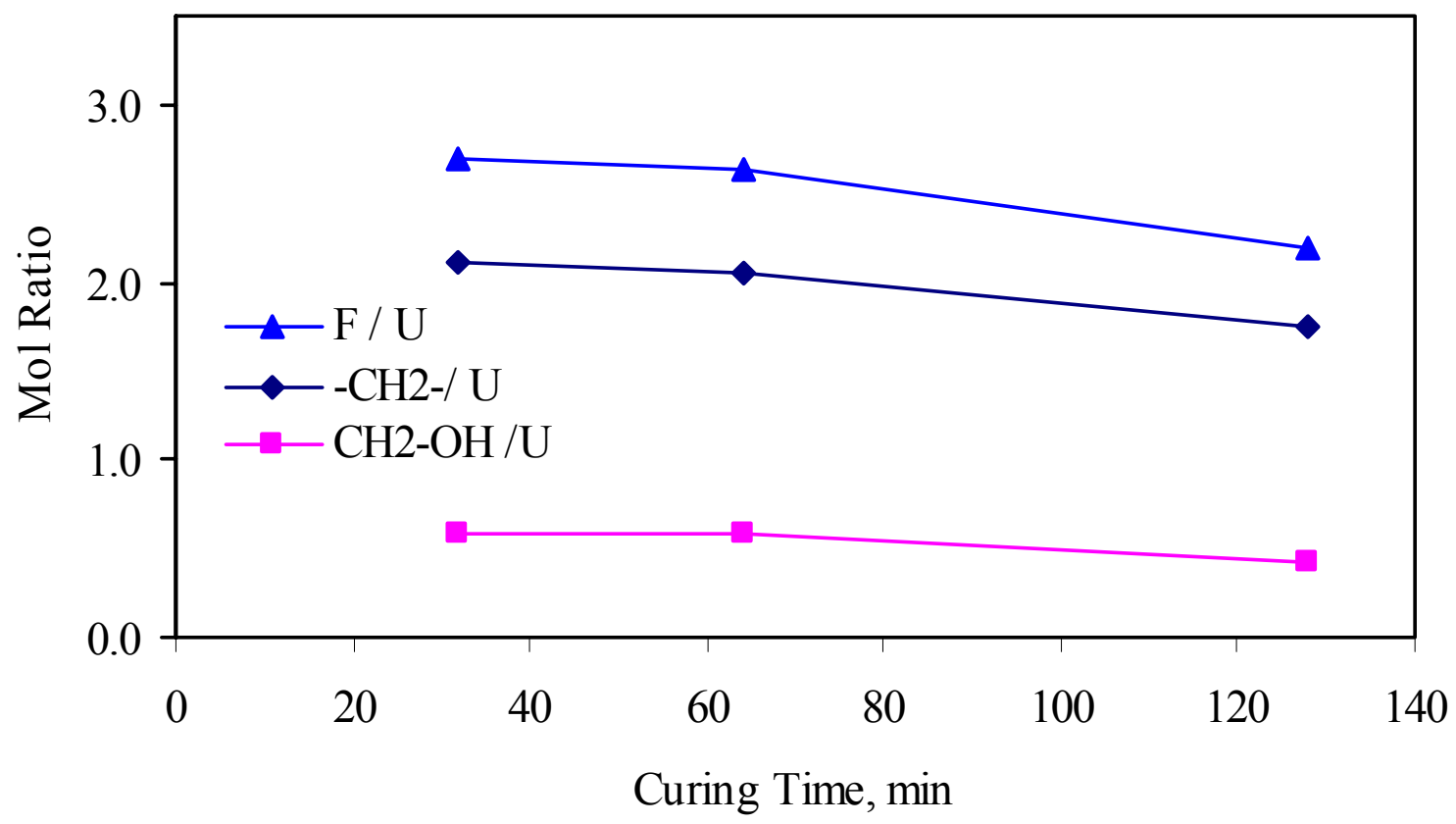


The data in Figure IV.15 summarizes the condensation chemistry of UF resin. These results clearly indicate that as curing proceeds we see a decrease in formaldehyde.

\section{DSC Studies.}

The interactions between the cationic starch, UF and PFa were evaluated by DSC analysis. Figure IV.16 provides a typical experimental data. The results of DSC analysis with varying amounts of cationic starch and UF and PF resins are summarized Table IV.4

Figure IV.16: DSC Data for PFa

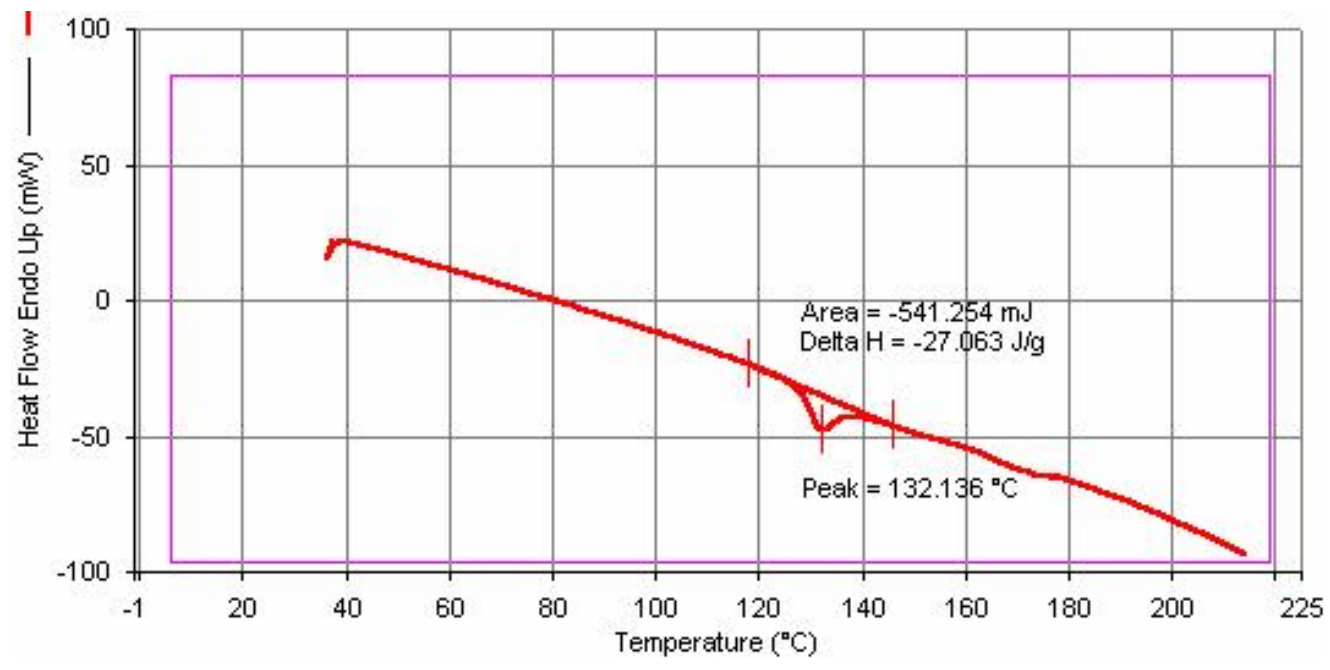


Table IV.4 DSC Analysis of UF and PF Resins Reinforced with Cationic Starch (CS)

$\begin{array}{llc}\text { Resin } & \text { Peak Temperature } /{ }^{\circ} \mathrm{C} & (-) \text { Delta } \mathrm{H}(\mathrm{J} / \mathrm{gr}) \\ \mathrm{PFa} & 132.1 & 27.1 \\ \mathrm{PFa}+10 \% \mathrm{CS} & 128.8 & 23.8 \\ \mathrm{PFa}+15 \% \mathrm{CS} & 127.4 & 21.0 \\ \mathrm{PFa}+20 \% \mathrm{CS} & 126.8 & 20.2 \\ \mathrm{UF} & 141.0 & 33.7 \\ \mathrm{UF}+10 \% \mathrm{CS} & 134.9 & 44.2 \\ \mathrm{UF}+20 \% \mathrm{CS} & 133.9 & 20.1\end{array}$

The DSC results were consistent with our gel studies and board studies, in each case the addition of cationic starch lowered the peak temperature suggesting a lower temperature for the cure temperature to occur. 


\section{Evaluating the Role of Additive Enhanced Curing of UF and PF Boards at Lower Energy Requirements.}

The studies of the prior sections clearly identified three different additives which have not been previously reported in the literature that could enhance resin cure rates. In addition, the composites boards prepared with additives provided enhanced physical properties including internal bond and reduced water absorption and thickness swelling. The remaining challenge in this program was to demonstrate the viability of employing these additives to lower the cure temperatures employed to prepare composite boards.

The overall experimental procedure employed to assess the potential of lowering press temperatures was by preparing the boards at standard press temperatures and then repeating this procedure at lower temperatures with and without additives. All these studies were accomplished in a laboratory setting employing the experimental protocols described in chapter II.

\section{Reducing OSB Press Temperatures via Additive Technologies.}

The results from preparing OSB boards with PFa with press temperatures of 375, 250 and $200{ }^{\circ} \mathrm{F}$ are summarized in Figure V.1 to V.5. The addition of $5 \%$ cure additive ( $\%$ additive is with respect to resin) was shown to provide enhanced strength and water stabilization properties.

Figure V.1: Two Hour Thickness Swelling for OSB Boards Prepared with 5\% (Based on Resin Mass) Nanoclay, Zeolite and Cationic Starch Employing PFa Resin.

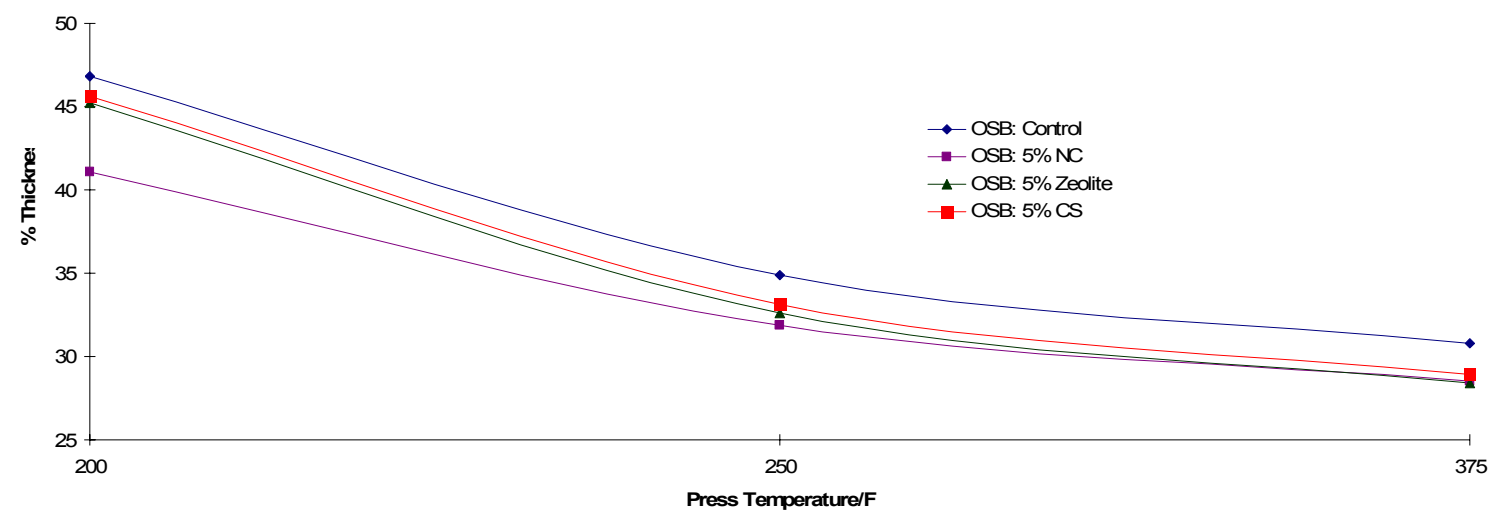


Figure V.2: $\quad$ Twenty-Four Hour Thickness Swelling for OSB Boards Prepared with 5\% (Based on Resin Mass) Nanoclay, Zeolite and Cationic Starch Employing PF?? Resin.

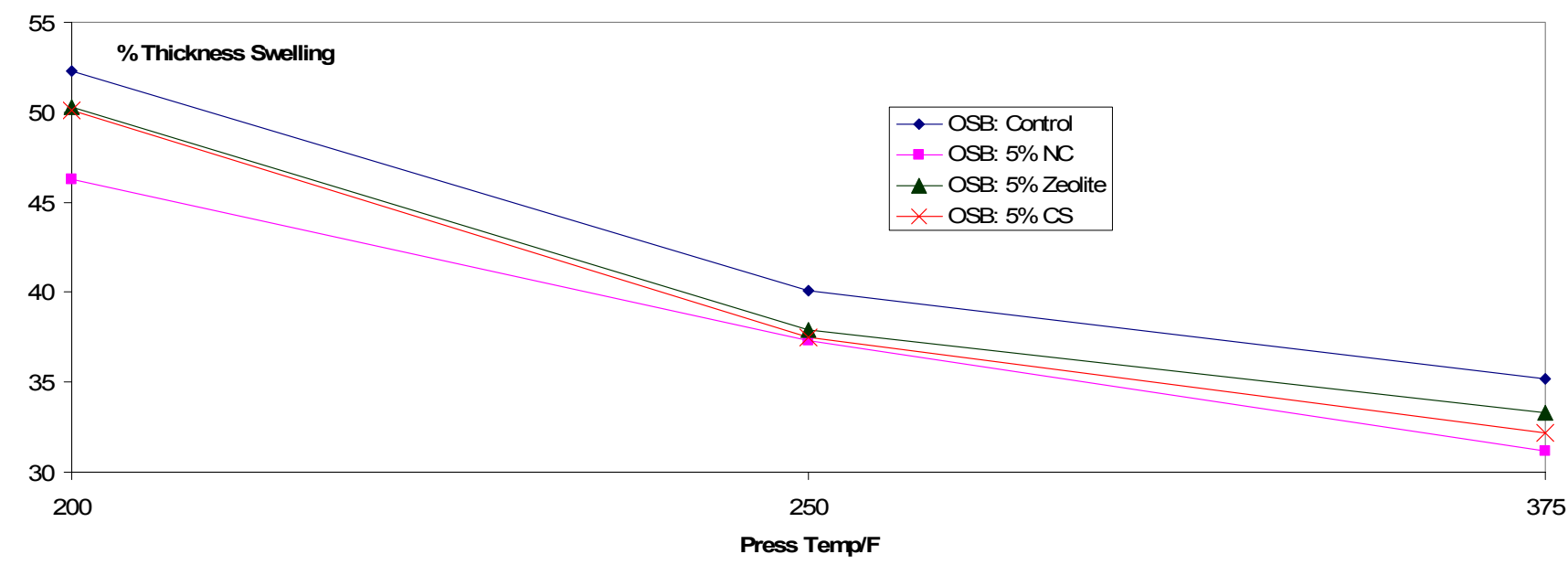

Figure V.3: Two Hour Water Absorption for OSB Boards Prepared with 5\% ((Based on Resin Mass) Nanoclay, Zeolite and Cationic Starch Employing PFa Resin.

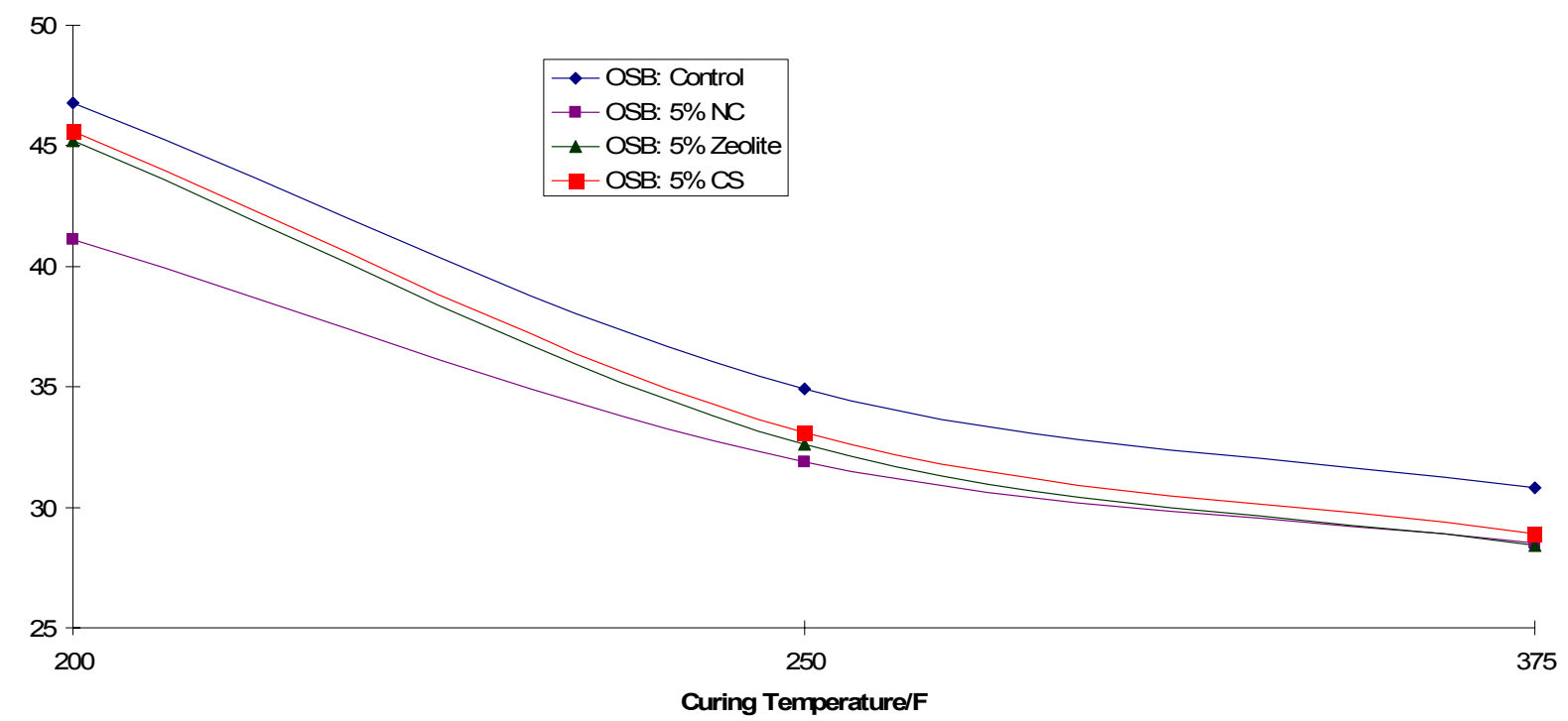


Figure V.4: Twenty Four Hour Water Absorption for OSB Boards Prepared with 5\% (Based on Resin Mass) Nanoclay, Zeolite and Cationic Starch Employing PFa Resin.

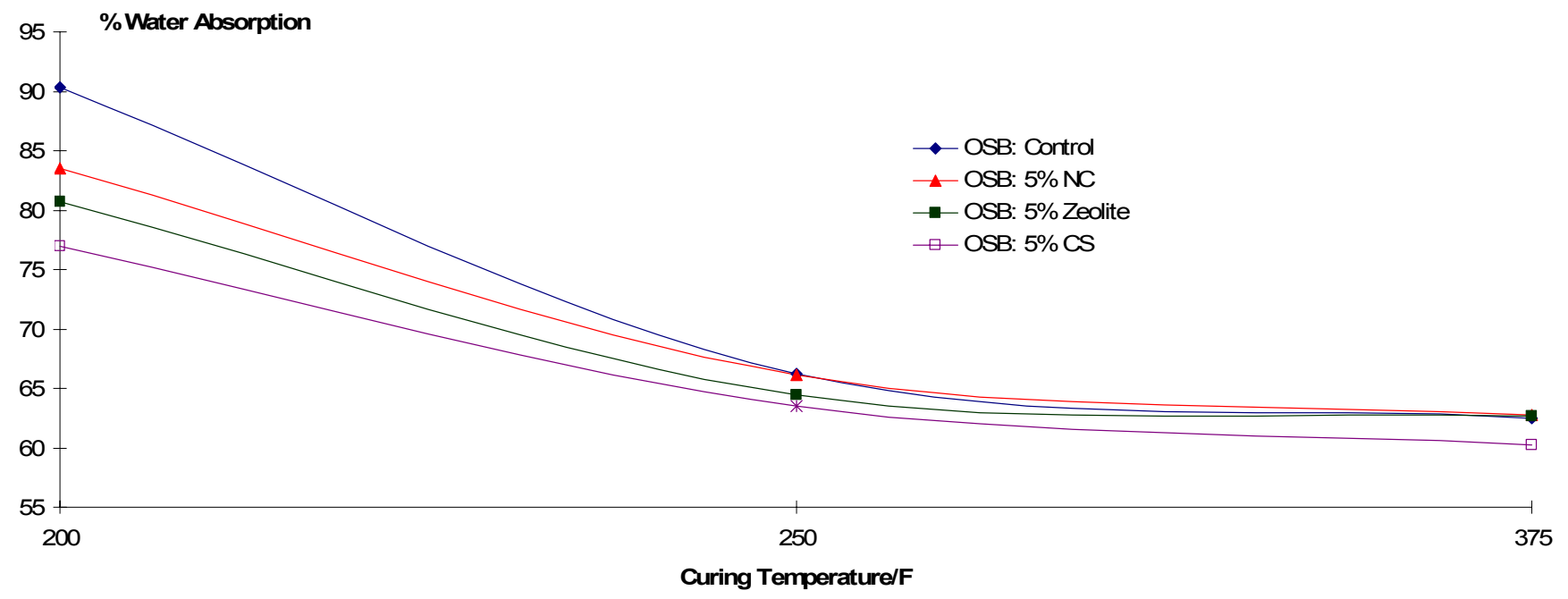

Figure V.5: IB-Properties for OSB Boards Prepared with 5\% (Based on Resin Mass) Nanoclay, Zeolite and Cationic Starch Employing PFa Resin.

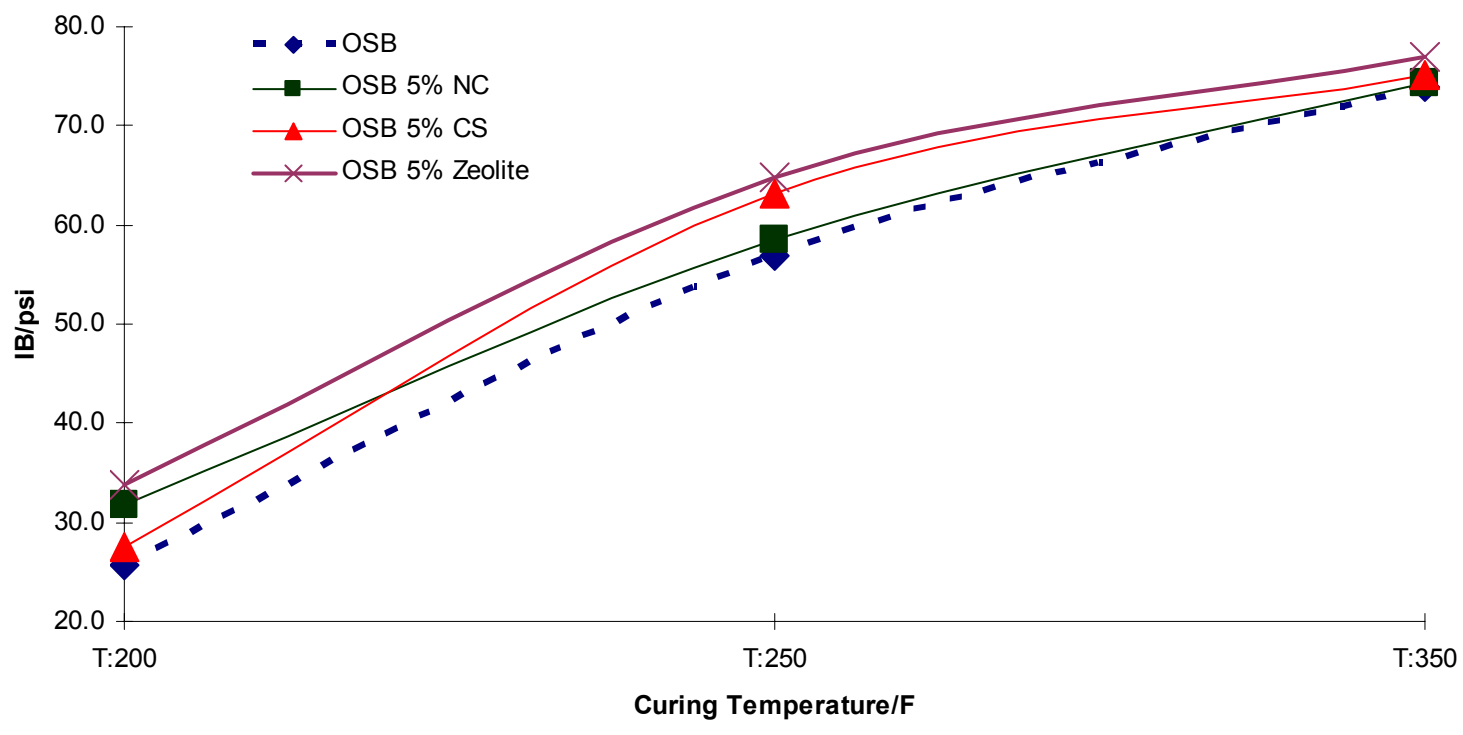

Depending on OSB product specifications, our results suggest that the addition of one of the three cure additives studied in this program (see Fig. V.1 V.5) can decrease press 
temperatures by $10-25 \%$ while still yielding an OSB product with the same physical properties.

\section{Reducing MDF Press Temperatures via Additive Technologies.}

Following the same approach as highlighted above, control and additive MDF boards were prepared at three temperatures and physical properties were determined. The results of these studies are reported in Figure V. $6-.9$.

Figure V.6: Two Hour Thickness Swelling for MDF Boards Prepared with 5\% (Based on Resin Mass) Nanoclay, Zeolite and Cationic Starch Employing UF Resin.

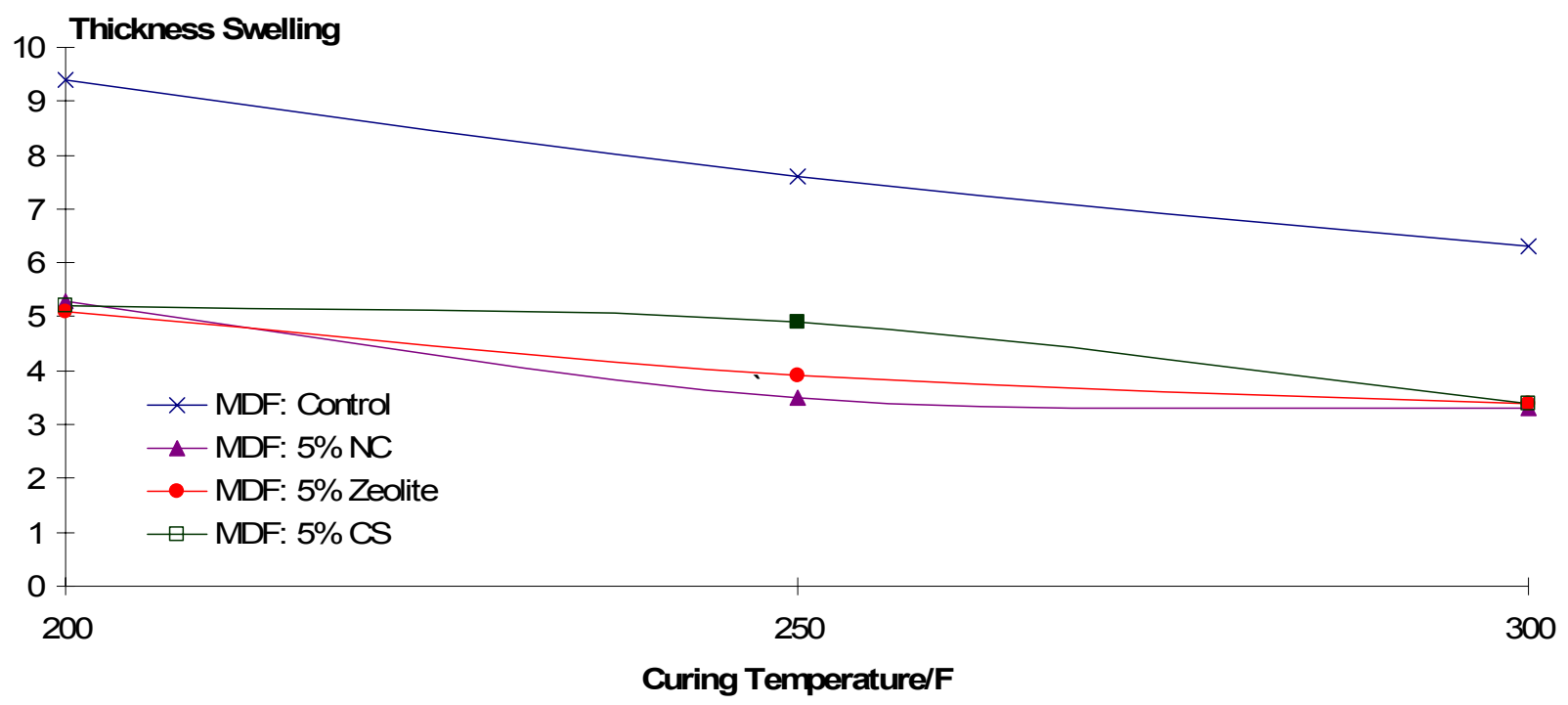


Figure V.7: Twenty-Four Hour Thickness Swelling for MDF Boards Prepared with 5\% (Based on Resin Mass) Nanoclay, Zeolite and Cationic Starch Employing UF Resin.

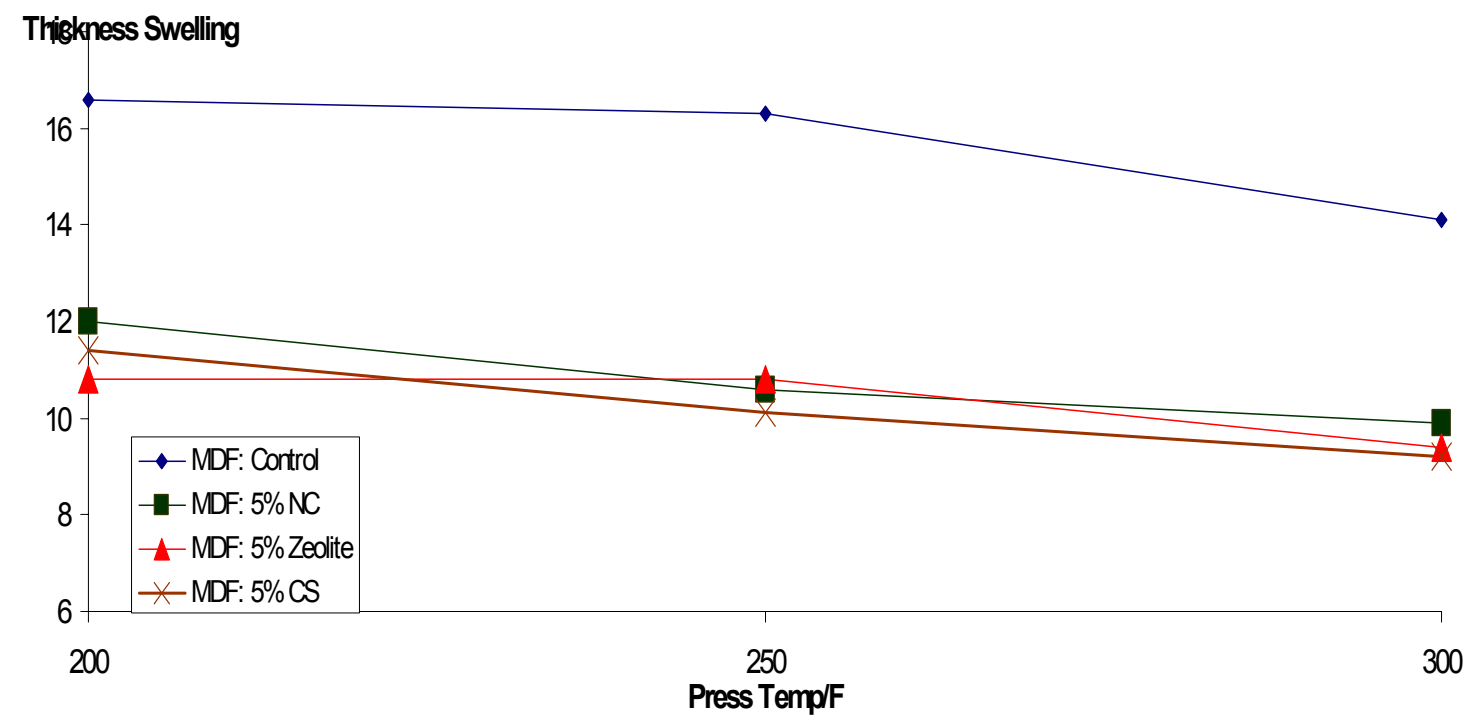

Figure V.8: Two Hour Water Absorption for MDF Boards Prepared with 5\% (Based on Resin Mass) Nanoclay, Zeolite and Cationic Starch Employing UF Resin.

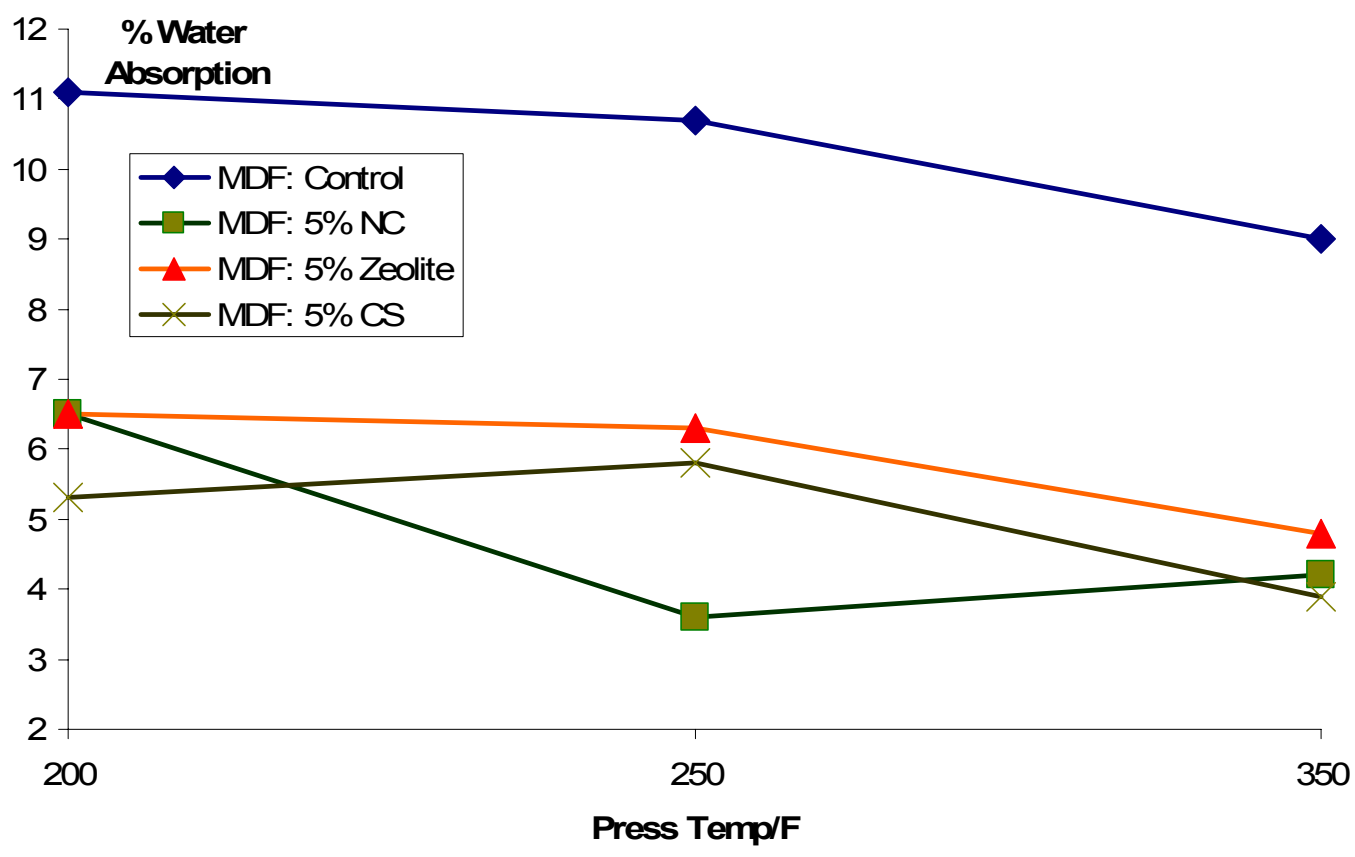


Figure V.9: Twenty-Four Hour Water Absorption for MDF Boards Prepared with 5\% (Based on Resin Mass) Nanoclay, Zeolite and Cationic Starch Employing UF Resin.

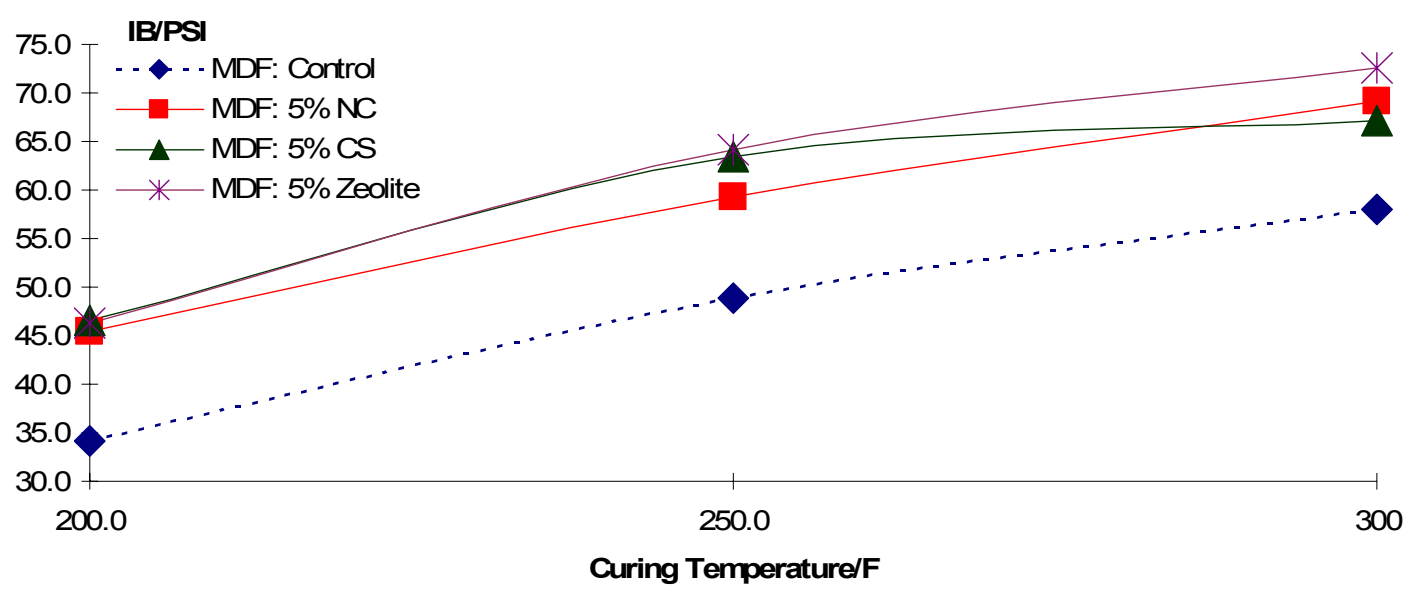

The results of the additives studied on MDF properties were even more promising than OSB. Significant improvements in IB strength properties and accompanying water stabilization properties were noted at all three temperatures studied.. Depending on product specifications, the results in Figures V.6 to V.9 suggest the potential of reducing the press temperature by at least $15 \%$. 


\section{Reducing PB Press Temperatures via Additive Technologies.}

Following the same approach as highlighted above for MDF and OSB, control and additive $\mathrm{PB}$ boards were prepared at three temperatures and physical properties were determined and are reported in Figure V.10 - .13 and Table V.1.

Figure V.10: Two Hour Thickness Swelling for PB Boards Prepared with 5\% (Based on Resin Mass) Nanoclay, Zeolite and Cationic Starch Employing UF Resin.

\section{\% Thickness Swelling}

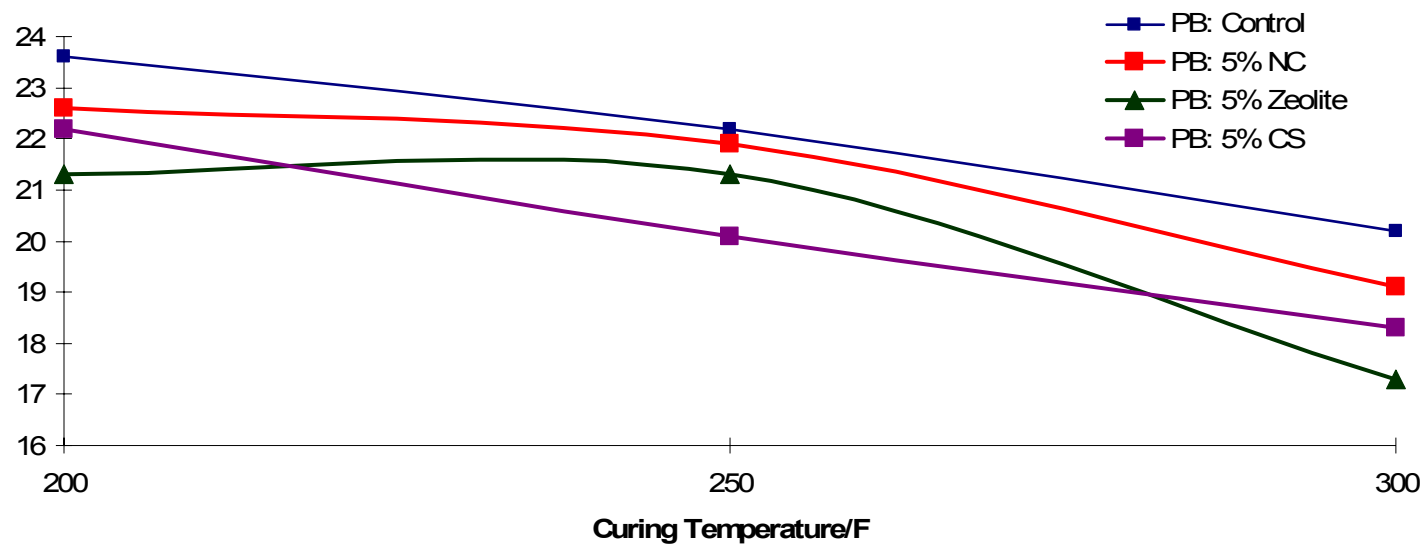

Figure V.11: Twenty-Four Hour Thickness Swelling for PB Boards Prepared with 5\% (Based on Resin Mass) Nanoclay, Zeolite and Cationic Starch Employing UF Resin.

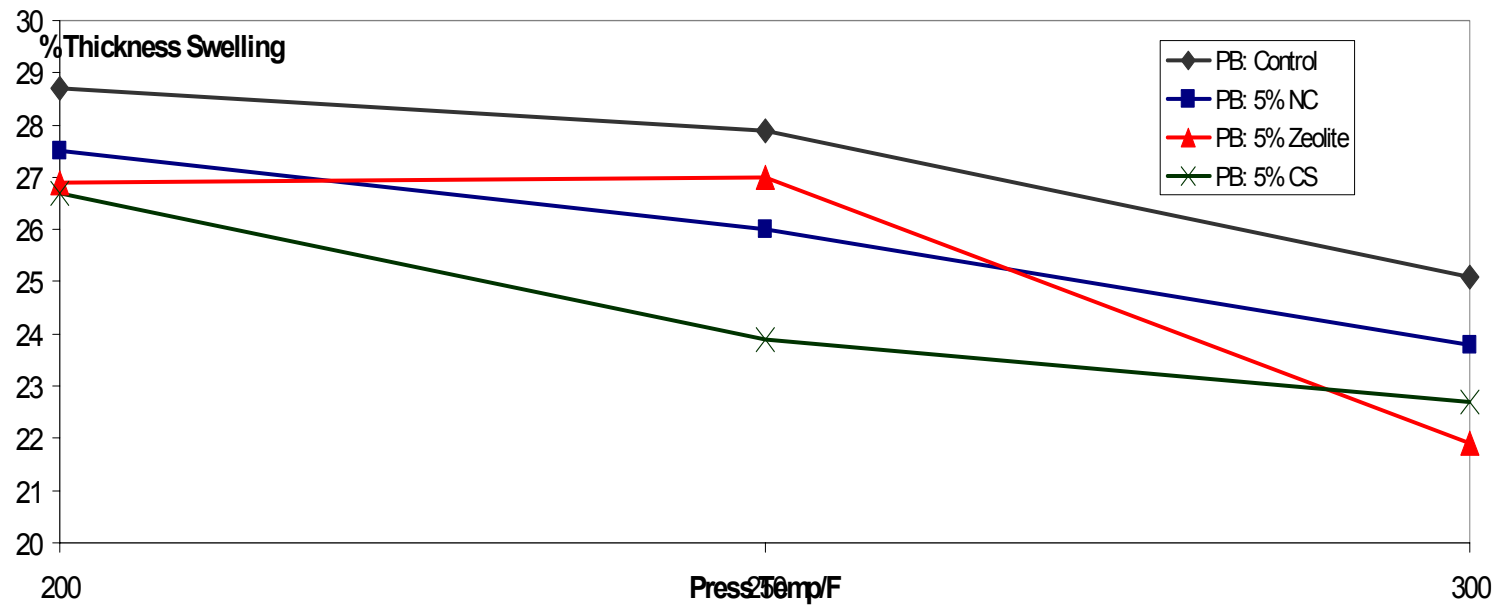


Figure V.12: Two Hour Water Absorption for PB Boards Prepared with 5\% (Based on Resin Mass) Nanoclay, Zeolite and Cationic Starch Employing UF Resin.

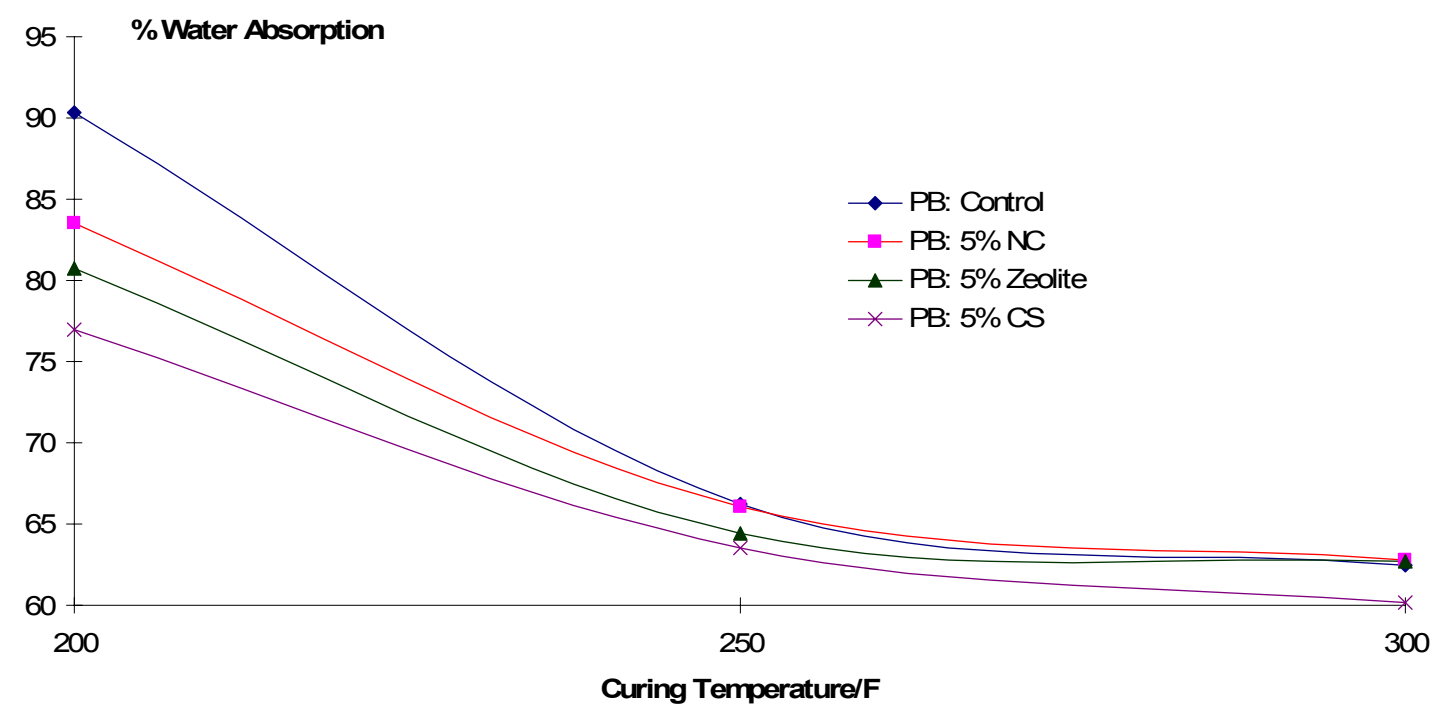

Figure V.13: Twenty-Four Hour Water Absorption for PB Boards Prepared with 5\% (Based on Resin Mass) Nanoclay, Zeolite and Cationic Starch Employing UF Resin.

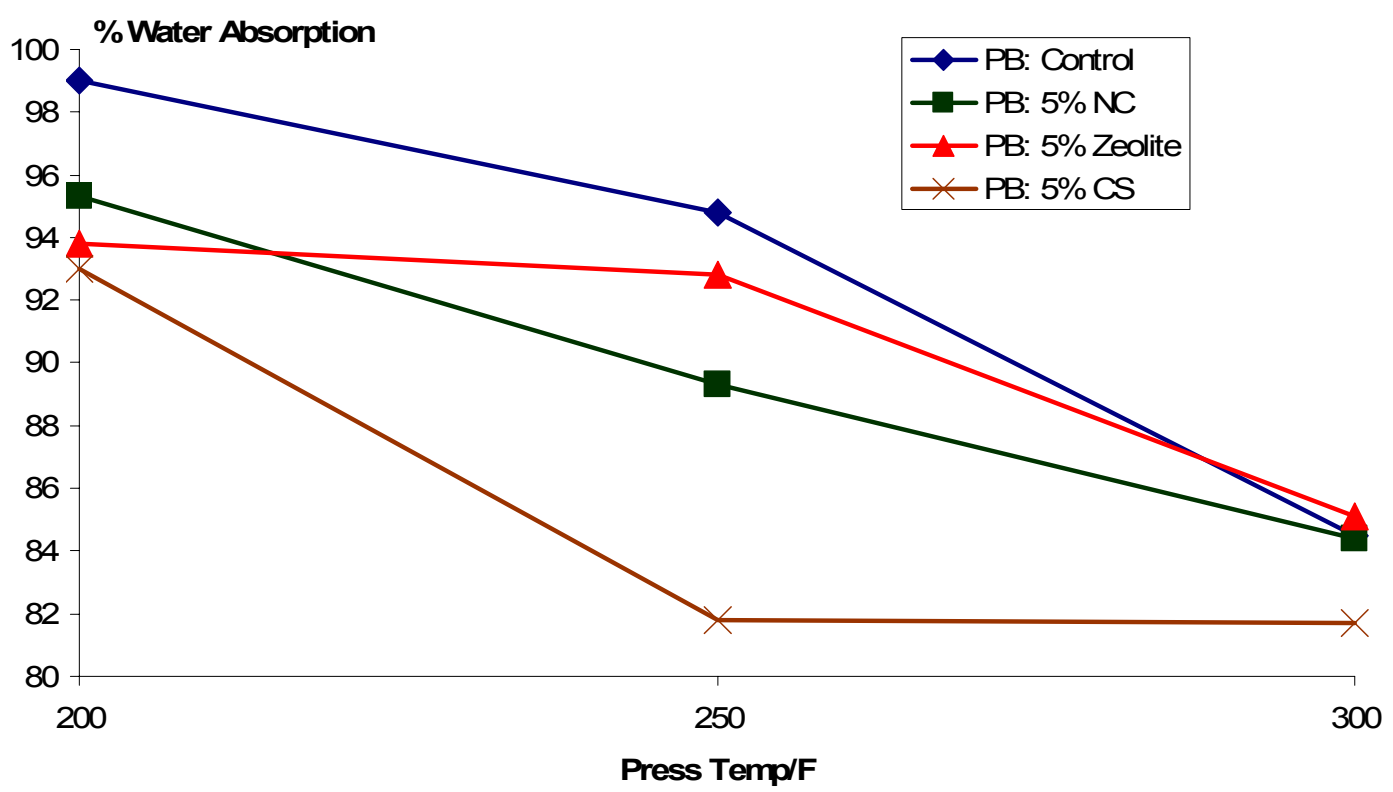


Table V.1: IB Properties for PB Boards Prepared with 5\% (Based on Resin Mass) Nanoclay, Zeolite and Cationic Starch Employing UF Resin.

$\begin{array}{lllll}\text { Press } & \text { PB } & \text { PB } & \text { PB } & \text { PB } \\ \text { Temperature/F } & \text { Control } & 5 \% \text { Nanoclay } & 5 \% \text { Zeolite } & 5 \% \text { CS } \\ 200 & 5.7 & 7.9 & 8.1 & 8.2 \\ 250 & 7.8 & 10.2 & 8.0 & 10.0 \\ 300 & 14.3 & 15.5 & 15.5 & 16.1\end{array}$

The results of the additives studied on PB properties were more promising than OSB. Significant improvements in IB strength properties and accompanying water stabilization properties were observed for the boards reinforced with the three additives under study. Depending on product specifications, the results in Figures V.6 to V.9 suggest the potential of reducing the press temperature by at least $15 \%$.

The final studies in this program were directed at assessing the viability of combining additives for an enhance physical properties for composite boards as summarized Figure V.14 and V.15

Figure V.14: Water Absorption and Thickness Swelling Properties for OSB Boards Prepared with Additive Mixtures at $250^{\circ} \mathrm{F}$.

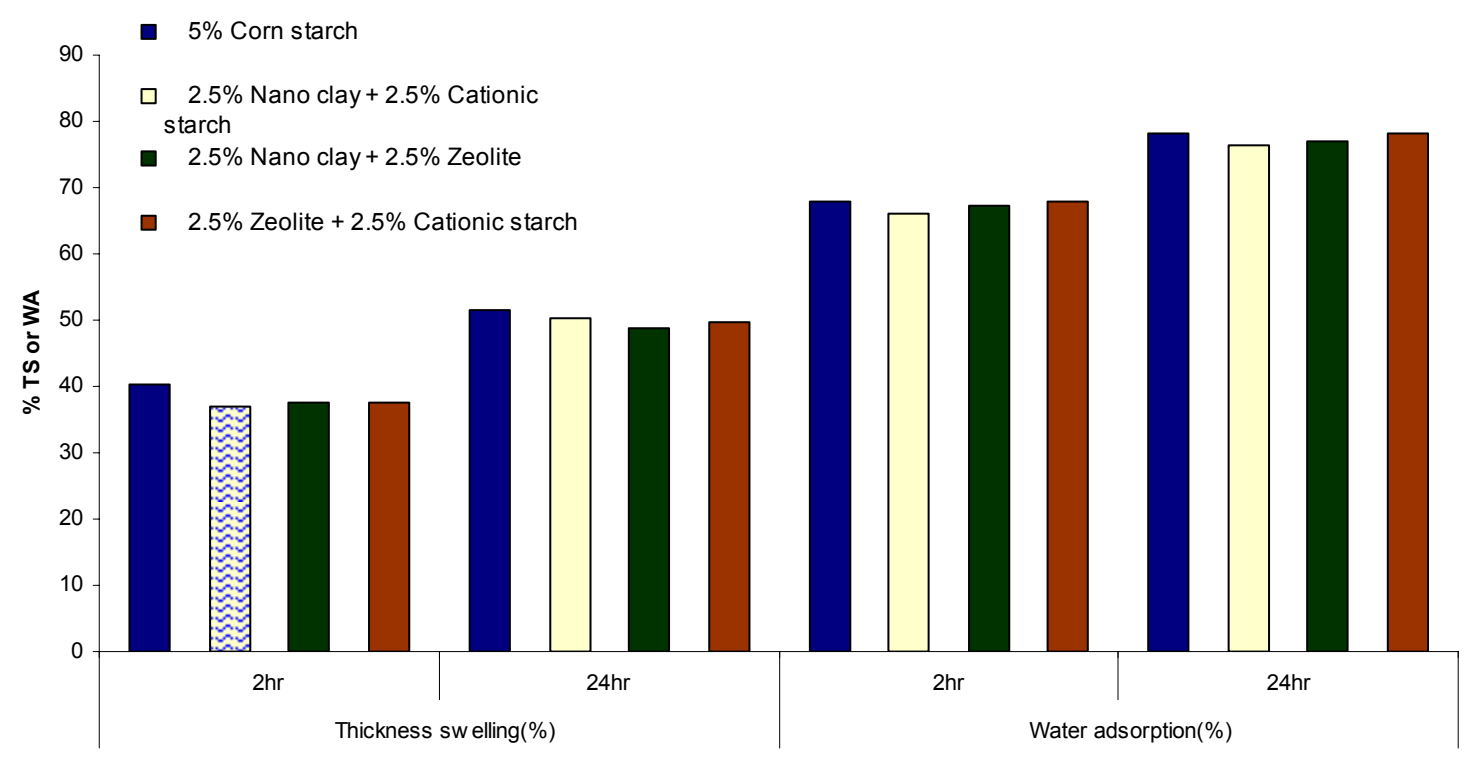


Figure V.15: Water Absorption and Thickness Swelling Properties for MDF Boards Prepared with Additive Mixtures at $250{ }^{\circ} \mathrm{F}$.

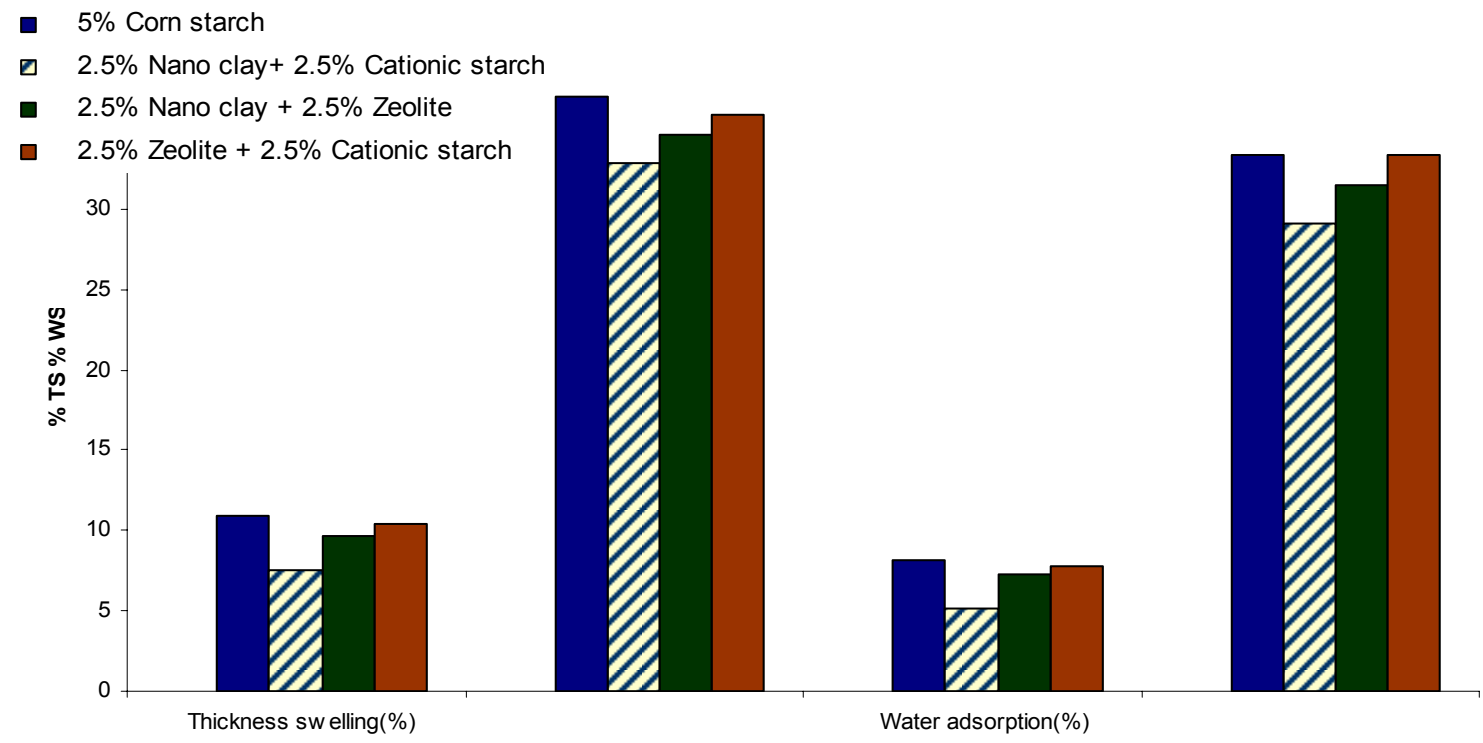

The results of this final study did not indicate any additional advantages from using mixtures of cationic starch, nanoclay or zeolite.

\section{Conclusions:}

In summary, the incorporation of nanoclay, zeolite, or cationic starch provides distinct benefits for OSB, MDF and PB board production. Enhancements in IB, water absorption and thickness swelling provide a viable approach to lowering press energy requirements by $10-25 \%$ depending on product specifications. An exciting advantage of these additives is that all are commercially available and are amendable to commercial applications. Finally, all additives can be readily incorporated into modern composite board production facilities with little effort. These results and the corresponding extractives complete this program. It provides board producers new additives technologies and treatments to enhance board products while reducing energy requirements 


\section{Acknowledgments:}

The authors would like to thank the U.S. Department of Energy (DOE) and the member companies of the Institute of Paper Science and Technology for their support of this research. However, any opinions, findings, conclusions, or recommendations expressed herein are those of the authors(s) and do not necessarily reflect the views of DOE.

\section{Literature Cited}

ASTM, American Society for Testing and Materials, West Conshohocken, PA (1999).

Bagley, E.B., G.F. Fanta, W.M. Doane, L.A. Gugliemelli, and C.R. Russell. 1977.

Composite composition from graft polymerized rigid fillers. U.S. patent 4,026,849

Baldwin, R.F. 1995. Plywood and veneer-based products. Miller Freeman Books.

Pp.256-277.

Batubenga, D.B., A. Pizzi, A. Stephanou, R. Krause, and P. Cheesman. 1995.

Isocyanate/phenolics wood adhesives by catalytic acceleration of copolymerization.

Holzforschung. 48:35-40

Bobu, E., G. Benea, and M. Bacaran. 1997. Performance and limits of starch as papermaking additives. Cellulose Chem. Technol. 31: 499-513

Buchert, Johanna; Mustranta, Annikka; Spetz, Peter; Ekman, Rainer; Holmbom, Bjarne. Enzymatic control of wood extractives. Appita Annual Conference Proceedings (2000), 54th(Vol. 2), 571-573. 
Carotenuto, G.; Nicolais, L. Kinetic study of phenolic resin cure by IR spectroscopy. Journal of Applied Polymer Science (1999), 74(11), 2703-2715.

Cazes, Mrs. J. Examination of various phenol - formaldehyde resins by infrared spectrophotometry. Double-Liaison (1962), No. 88 17-22.

Chandra, Richard P.; Ragauskas, Arthur J.. Evaluating laccase -facilitated coupling of phenolic acids to high-yield kraft pulps. Enzyme and Microbial Technology (2002), 30(7), 855-861.

Conner, Anthony H.; Lorenz, Linda F.; Hirth, Kolby C. Accelerated cure of phenolformaldehyde resins: studies with model compounds. Journal of Applied Polymer Science (2002), 86(13), 3256-3263.

Conner A. H., and L. F. Lorenz. 1986. Carbohydrate modified phenol-formaldehyde resins. J. of Wood Chemistry and Technology. 6(4):591-613.

Daisy N.K.; Leeper, D.L.; Australian Paptent No., 597,725 (1987).

Devallencourt, C., J.M. Saiter, and D. Capitaine. 2000. Reactions between melamine formaldehyde resin and cellulose. Journal of Applied Polymer Science. 78:1884-1896.

Dunky, M. Urea-formaldehyde (UF) adhesive resins for wood. International Journal of Adhesion and Adhesives (1998), 18(2), 95-107.

Felby, Claus; Hassingboe, Jens; Lund, Martin. Pilot-scale production of fiberboards made by laccase oxidized wood fibers: board properties and evidence for cross-linking of lignin. Enzyme and Microbial Technology (2002), 31(6), 736-741 
Frihart, Charles R. Durable wood bonding with epoxy adhesives. Proceedings of the Annual Meeting of the Adhesion Society (2003), 26th 476-478.

Gutowski, W. S.; Widsten, P.; Li, S.; Cerra, T.; Molenaar, S.; Spicer, M. Improving the adhesion strength of wood cross-lap joints by flame treatment and solvent extraction. Appita Annual Conference and Exhibition (2005), 59th 173-177.

Hassingboe, J.; Lawther, J. M.; Felby, C.. Influence of extractives on enzymic catalyzed bonding of Norway spruce TMP fibers. International Conference on Biotechnology in the Pulp and Paper Industry, 7th, Vancouver, B. C., June 16-19, 1998 (1998), A A125A128

Jada, Sivananda S. The structure of urea-formaldehyde resins. Journal of Applied Polymer Science (1988), 35(6), 1573-92.

Janowiak J. J., and B. S. Carlson. 1998. Methyl glucoside and lignosulphonate extenders for use with particleboard UF resins. Forest Products Journal. 48(11/12):65-70.

Johnson S. E., and F. A. Kamke. 1994. Carbohydrate-based extender for wood-particle composites. Forest Products Journal. 44(3):46-48.

Kozlowski, R.; Mieleniak, B.; Helwig, M.; Przepiera, A. Flame-resistant lignocellulosicmineral composite particleboards. Polymer Degradation and Stability (1999), 64(3), 523-528.

Kronotec A.G., Manufacture of a wood-based floor panel with improved characteristics, suitable for humidity application. Eur. Pat. Appl. (2005), 10 pp. CODEN: EPXXDW EP 1493879 A1 20050105 CAN 142:76382 AN 2005:9335

Lund, M.; Ragauskas, A. J. . Enzymatic modification of kraft lignin through oxidative coupling with water-soluble phenols. Applied Microbiology and Biotechnology (2001), 55(6), 699-703. 
Mansfield, Shawn D.; Esteghlalian, Ali R. Applications of biotechnology in the forest products industry. ACS Symposium Series (2003), 855(Applications of Enzymes to Lignocellulosics), 2-29.

Mauer H. 2001 Starch and starch Products in Surface Sizing and paper coating. Tappi Press. pp.129-141.

Miller, H. A. 1977. Particle board manufacture. Noyes Data Corporation. Pp. 71-132

Mustranta, Annikka; Buchert, Johanna; Spetz, Peter; Holmbom, Bjarne. Treatment of mechanical pulp and process waters with lipase. Nordic Pulp \& Paper Research Journal (2001), 16(2), 125-129.

Orth, George O., Jr. Phenol-aldehyde resin adhesive compositions. U.S. (1972), 2 pp. Division of U.S. patent 3,522,128.

Park, Byung-Dae; Riedl, Bernard. 13C- NMR study on cure-accelerated phenolformaldehyde resins with carbonates. Journal of Applied Polymer Science (2000), $77(4), 841-851$.

Park, Byung-Dae; Riedl, Bernard; Hsu, Ernest W.; Shields, Jack. Differential scanning calorimetry of phenol-formaldehyde resins cure-accelerated by carbonates. Polymer (1998), 40(7), 1689-1699.

Park, B., and B. Riedl. 13C-NMR study on cure-accelerated phenol-formaldehyde resins with carbonates. J. of Applied Polymer Science. (2000) 77:1284-1293

Pizzi, A.; Garcia, R.; Wang, S. On the networking mechanisms of additives-accelerated phenol-formaldehyde polycondensates. Journal of Applied Polymer Science (1997), $66(2), 255-266$. 
Pizzi, A , and A. Stephanou. 1994. On the chemistry, behavior, and cure acceleration of phenol-formaldehyde resins under very alkaline. Journal of Applied Polymer Science. 49:2157-2170.

Pizzi, A , and A. Stephanou. 1994. Phenol-formaldehyde wood adhesives under very alkaline conditions-Part2:Esters curing acceleration, its mechanism and applied results. Holzforschung. 48:150-156.

Poljansek, I.; Krajnc. M. Quantitative FT- IR spectroscopy characterization of phenol formaldehyde prepolymer resins. World Congress of Chemical Engineering, 7th, Glasgow, United Kingdom, July 10-14, (2005).

Poljansek, Ida; Sebenik, Urska; Krajnc, Matjaz. Characterization of phenol- urea formaldehyde resin by inline FTIR spectroscopy. Journal of Applied Polymer Science (2006), 99(5), 2016-2028.

Proszyk, Stanislaw; Krystofiak, Tomasz. Some aspects of hardening processes of amino resin adhesives in the presence of selected wood extracts. Part I. Kinetics of gelation process. Vybrane Procesy pri Chemickom Spracovani Dreva (1996), 317-323.

$\mathrm{Pu}$, Yunqiao; Ziemer, Cherie; Ragauskas, Arthur J. CP/MAS 13C NMR analysis of cellulase treated bleached softwood kraft pulp. Carbohydrate Research (2006), 341(5), $591-597$

Robertson, J. E., and R. R. Robrtson. 1977, Review of filler and extender quality evaluation. Forest Products Journal. 27(4):30-38.

Sanjuan, R., J. Rivera, and F. J. Fuentes. 1999. Evaluation of adhesive mixtures of phenol-formaldehyde and organosolv lignin of sugarcane bagasse. Holz als Roh und Werkstoff. 57:418 
Sellers T. 1985. Plywood and adhesive technology. Mercel Dekker. Pp 383-395.

Shimoto, Hidesato. Enzymatic pitch control of mechanical pulp production process. Kami Pa Gikyoshi (1999), 53(9), 1147-1152.

Speaks, Jerry R.; Campbell, Roger O.; Veal, Michael A. Pretreatment of wood particulates with extraction solvents for removal of wood extractives. PCT Int. Appl. (1999),

Suzuki, Keizo. The nano-scale view in clay minerals. Journal of the Society of Inorganic Materials, Japan (2001), 295 558-567.

Tohmura, Shin-Ichiro. Acceleration of the cure of phenolic resin adhesives VII: Influence of extractives of merbau wood on bonding. Journal of Wood Science (1998), 44(3), 211-216.

Tomita, B., M. Ohyama, and C. Hse. 1992. Cocondesator of Urea with methyol phenols in acidic condition. Journal of Polymer Science, Part A. 30:1615-1624.

Tomita, B., M. Ohyama, and C. Hse. 1994. Synthesis of phenol-formaldehyde cocondensed resin from UF-concentrate and phenol. Holzforschung. 48:522-526.

Tsarev, G.; Leonovich, A. Use of lignin and extractives from wood as binders in the manufacture of fiberboards. Zbornik Referatov - Sympozium "Pokroky vo Vyrobe a Pouziti Lepidiel v Drevopriemysle (1995), 12th 123-32.

Zeng Q H; Yu A B; Lu G Q; Paul D R Clay-based polymer nanocomposites: research and commercial development. Journal of nanoscience and nanotechnology (2005), 5(10), 1574-92. 
Zhang, X.; Renaud, S.; Paice, M. The potential of laccase to remove extractives present in pulp and white water from TMP newsprint mills. Journal of Pulp and Paper Science (2005), 31(4), 175-180.

Vasishth; R.C.; Chandramouli P. Thermally hardenable phenol formaldehyde resin. Ger. Offen. (1975), 35 pp. Addn to Ger. Offen. 2,436,893. CODEN: GWXXBX DE 251632219751030 CAN 84:45222 